\title{
Ras Signaling Mechanisms Underlying Impaired GluR1- Dependent Plasticity Associated with Fragile X Syndrome
}

\author{
Hailan Hu, ${ }^{1 *}$ Yi Qin, ${ }^{1,3 *}$ Genrieta Bochorishvili, ${ }^{1}$ Yinghua Zhu, ${ }^{1}$ Linda van Aelst, ${ }^{3}$ and J. Julius Zhu ${ }^{1,2}$ \\ Departments of ${ }^{1}$ Pharmacology and ${ }^{2}$ Neuroscience, University of Virginia School of Medicine, Charlottesville, Virginia 22908, and ${ }^{3}$ Center for Cancer \\ Research, Cold Spring Harbor Laboratory, Cold Spring Harbor, New York 11724
}

Fragile X syndrome, caused by the loss of FMR1 gene function and loss of fragile $\mathrm{X}$ mental retardation protein (FMRP), is the most commonly inherited form of mental retardation. The syndrome is characterized by associative learning deficits, reduced risk of cancer, dendritic spine dysmorphogenesis, and facial dysmorphism. However, the molecular mechanism that links loss of function of FMR1 to the learning disability remains unclear. Here, we report an examination of small GTPase Ras signaling and synaptic AMPA receptor (AMPA-R) trafficking in cultured slices and intact brains of wild-type and FMR1 knock-out mice. In FMR1 knock-out mice, synaptic delivery of GluR1-, but not GluR2L- and GluR4-containing AMPA-Rs is impaired, resulting in a selective loss of GluR1-dependent long-term synaptic potentiation (LTP). Although Ras activity is upregulated, its downstream MEK (extracellular signal-regulated kinase kinase)-ERK (extracellular signal-regulated kinase) signaling appears normal, and phosphoinositide 3-kinase (PI3K)-protein kinase B (PKB; or Akt) signaling is compromised in FMR1 knock-out mice. Enhancing Ras-PI3K-PKB signaling restores synaptic delivery of GluR1-containing AMPA-Rs and normal LTP in FMR1 knock-out mice. These results suggest aberrant Ras signaling as a novel mechanism for fragile $\mathrm{X}$ syndrome and indicate manipulating Ras-PI3K-PKB signaling to be a potentially effective approach for treating patients with fragile $\mathrm{X}$ syndrome.

Key words: autism; AMPA receptor trafficking; Ras-PI3K signaling; cancer risk; mental retardation; dendritic spine dysmorphogenesis; facial dysmorphism

\section{Introduction}

Fragile $\mathrm{X}$ syndrome is caused by loss of fragile $\mathrm{X}$ mental retardation protein (FMRP), which modulates the functions of a large number of other proteins (O’Donnell and Warren, 2002; Bagni and Greenough, 2005). Patients with fragile X syndrome typically have a moderate learning disability with their intelligence quotient declining from $\sim 80$ at 5 years of age to $\sim 50$ through the pubertal years because of suboptimal intellectual growth (Loesch et al., 2004; Skinner et al., 2005). In FMR1 knock-out (KO) mice, a mouse model for fragile X syndrome (The Dutch-Belgian Fragile X Consortium, 1994), NMDA-R-dependent long-term depression (LTD) is unchanged, whereas metabotropic glutamate receptor (mGluR)-dependent LTD is modestly upregulated by $\sim 10-15 \%$ (Huber et al., 2002). It is controversial whether there is

\footnotetext{
Received Dec. 26, 2007; revised May 21, 2008; accepted June 23, 2008.

This work was supported in part by the Alfred P. Sloan foundation, the Department of Defense, the Fragile X Research Foundation, the National Institutes of Health, the National Science Foundation, and the Whitehall Foundation. H.H. is a postdoctoral fellow of the Damon Runyon Cancer Research Foundation. We thank John Lawrence, lan Macara, Robert Malinow, Ruth Stornetta, and members of the Zhu laboratory for critical comments and suggestions; David Mchedlishvili for technical assistance and help with some experiments; Katie Clapp and Mike Tranfaglia for insightful discussions of clinical observations; and Hong Wu for the constructs of PTEN mutants.

*H.H. and Y.Q. contributed equally to this work.

Correspondence should be addressed to J. Julius Zhu, Department of Pharmacology, University of Virginia School of Medicine, 1300 Jefferson Park Avenue, Charlottesville, VA 22908. E-mail: jjzhu@virginia.edu.

H. Hu's present address: Institute of Neuroscience, Chinese Academy of Sciences, Shanghai 200031, China.

Y. Qin's present address: Center for Cell Signaling, University of Virginia, Charlottesville, VA 22908.

DOI:10.1523/JNEUROSCI.1496-08.2008

Copyright $\odot 2008$ Society for Neuroscience $\quad$ 0270-6474/08/287847-16\$15.00/0
}

no change, a reduction, or complete loss of long-term potentiation (LTP) and whether there are mild or profound learning defects in FMR1 knock-out mice (D'Hooge et al., 1997; Van Dam et al., 2000; Li et al., 2002; Lauterborn et al., 2007). Thus, whether loss of FMRP impairs particular form(s) of synaptic plasticity and learning in human patients remains unclear.

Synaptic delivery of AMPA-Rs, dependent on small GTPase Ras signaling, plays key roles in synaptic transmission and potentiation (Malinow and Malenka, 2002; Thomas and Huganir, 2004; Tada and Sheng, 2006; Gu and Stornetta, 2007; Isaac et al., 2007). Accordingly, a number of diseases causing cognitive impairment are associated with aberrant Ras signaling (Costa and Silva, 2003; Thomas and Huganir, 2004; Schubbert et al., 2007). Fragile X syndrome shares behavioral disorders with some of these diseases (e.g., autism) (O'Donnell and Warren, 2002; Loesch et al., 2007), suggesting malfunctions of Ras signaling as a possible common cause. In addition, mRNAs translation and protein expression of Ras family GTPase regulators are altered in fragile X cells (Zhong et al., 1999; Brown et al., 2001; Zalfa et al., 2003). Moreover, downregulation of Ras signaling prevents spine maturation (Govek et al., 2005), a prominent feature associated with fragile X syndrome (Bagni and Greenough, 2005). Furthermore, aberrant Ras signaling is frequently linked to developmental disorders with facial dysmorphism (Schubbert et al., 2007), one of the major characteristics for patients with fragile $\mathrm{X}$ syndrome (O'Donnell and Warren, 2002). Finally, upregulation of Ras signaling is a common cause of cancer (Hanahan and Wein- 
berg, 2000). Patients with fragile X syndrome have a strikingly low incidence of cancer $(\sim 28 \%)$ compared with the normal population (Schultz-Pedersen et al., 2001), suggesting a downregulation of Ras signaling. Surprisingly, however, whether aberrant Ras signaling is responsible for fragile $\mathrm{X}$ syndrome has never been investigated.

In this study, we found that LTP was reduced by $\sim 50 \%$ in FMR1 knock-out mice because of selective impairment of synaptic trafficking of GluR1-, but not GluR2L- (the C-terminal splice variant of the GluR2 subunit) and GluR4-containing AMPA-Rs. Interestingly, the overall Ras activity was upregulated, but extracellular signal-regulated kinase kinase (MEK)-extracellular signal-regulated kinase (ERK) signaling appeared normal and phosphoinositide 3-kinase (PI3K)-protein kinase B (PKB) signaling was compromised in knock-out mice, suggesting defects in signal transduction between Ras and its downstream MEKERK and PI3K-PKB pathways. Notably, enhancing Ras-PI3K$\mathrm{PKB}$ signaling using two distinct approaches restored synaptic delivery of GluR1-containing AMPA-Rs and normal LTP in knock-out mice.

\section{Materials and Methods}

Biochemical analyses. Hippocampal extracts were prepared by homogenizing hippocampal CA1 regions isolated from either cultured slices or 2-week-old mouse brains (Zhu et al., 2002; Qin et al., 2005). Wild-type (WT) and FMR1 knock-out mice bred congenically on a C57BL/6 background were obtained from The Jackson Laboratory. Mice were genotyped by Dr. Sanford Feldman, Department of Comparative Medicine/ Animal Care Facility of the University of Virginia. To isolate the CA1 regions from intact mouse brains, hippocampi were quickly isolated and frozen with liquid $\mathrm{N}_{2}$, and CA1 regions were isolated from frozen hippocampi immediately before homogenization. Homogenizing solution contained 10 mм HEPES, $150 \mathrm{~mm} \mathrm{NaCl}, 10$ mм EDTA, 4 mм EGTA, 0.2 mM PMSF, 0.1 mu NaPPi, $0.5 \mathrm{~mm} \mathrm{NaF}, 1 \mathrm{~mm} \mathrm{Na} \mathrm{VO}_{4}, 0.0001 \%$ chymostatin, $0.0001 \%$ leupeptin, $0.0001 \%$ antipain, $0.0001 \%$ pepstatin, and $1 \%$ Triton. Membranes were blotted with anti-phospho-ERK (1:10000; Cell Signaling Technology), anti-phospho-phosphoinositide-dependent kinase 1 (PDK1) antibody (1:2000; Cell Signaling Technology), antiphospho-p308-PKB antibody (1:2000; Cell Signaling Technology), antiphospho-p845-GluR1 (1:800; Millipore), or anti-phospho-p831-GluR1 (1:1000; Millipore), and reblotted with anti-ERK (1:2000; Cell Signaling Technology), anti-PDK1 antibody (1:2000; Cell Signaling Technology), anti-PKB antibody (1:1000; Cell Signaling Technology), or anti-GluR1 (1:8000; Millipore). Active Ras was detected by affinity precipitation of Ras-GTP with glutathione $S$-transferase-linked Ras-binding domain of Raf1, as described in a previous study (de Rooij and Bos, 1997). The bound Ras-GTP was then eluted and Western blotted with anti-Ras antibody (1:1000; Transduction Laboratories). Western blots were quantified by chemiluminescence and densitometric scanning of the films under linear exposure conditions.

Constructs and expression. GluR1-GFP-IRES-Ras(wt)-RFP was made by subcloning GluR1-green fluorescent protein (GFP) and Ras(wt)-red fluorescent protein (RFP) into a pCITE vector with an internal ribosome entry site (IRES) as described previously (Zhu et al., 2005). Other constructs were made as described previously (Zhu et al., 2002; Qin et al., 2005). Constructs were expressed in CA1 neurons in hippocampal slices or in intact brains, using Sindbis virus or biolistics transfection. For in vitro expression, slices were prepared from postnatal 6- to 7-d-old mice, infected with virus or transfected using a gene gun after $6-8 \mathrm{~d}$ in vitro, and incubated in culture media and $5 \% \mathrm{CO}_{2}$ for $15 \pm 3 \mathrm{~h}$ before experiments. Biolistics transfection was efficient to get all cotransfected proteins expressed (Qin et al., 2005). Activation of the PI3K-PKB signaling pathway for $>24$ h induces significant changes in dendritic morphology (Jaworski et al., 2005; Kumar et al., 2005). We found that a brief expression of PTEN(dn)-RFP for $15 \pm 3 \mathrm{~h}$ in CA1 neurons of FMR1 knock-out mice has no significant effect on AMPA and NMDA responses, basic membrane properties, including the resting membrane potential, input resistance, and membrane capacity (supplemental Fig. S1, available at www.jneurosci.org as supplemental material). For pharmacological experiments, slices were maintained in culture media containing drugs and or agonists [i.e., histamine and 4-(m-chlorophenylcarbamoyloxy)-2butynyltrimethylammonium $(\mathrm{McN}-\mathrm{A}-343 ; \mathrm{McN})$ ] from the time they were infected or transfected for $15 \pm 3 \mathrm{~h}$ unless stated otherwise. For in vivo expression, postnatal 13- to 15-d-old mice, which were developmentally equivalent to the cultured slices we used (De Simoni et al., 2003), were initially anesthetized by an intraperitoneal injection of ketamine and xylazine (10 and $2 \mathrm{mg} / \mathrm{kg}$, respectively). Animals were then placed in a stereotaxic frame and a hole $\sim 1 \times 1 \mathrm{~mm}$ was opened above the right somatosensory cortex (Zhu and Connors, 1999). A glass pipette was used to penetrate into the hippocampus or barrel cortex according to stereotaxic coordinates and $\sim 100 \mathrm{nl}$ of viral solution was delivered into the hippocampal CA1 region or cortical layer $2 / 3$ by pressure injection (Qin et al., 2005; McCormack et al., 2006). After injection, animals were allowed to recover from the anesthesia and returned to the dam. To study synaptic trafficking of GluR1 in vivo, expression of constructs were made when the animals were awake, which was required for synaptic delivery of GluR1 (Qin et al., 2005). Approximately 12-16 h after injections, acute hippocampal or cortical slices were prepared for electrophysiology experiments.

Electrophysiology. Simultaneous whole-cell recordings were obtained from nearby infected/transfected and noninfected/nontransfected hippocampal CA1 or cortical layer $2 / 3$ pyramidal neuron pairs (Zhu, 2000; Zhu et al., 2000; Larkum and Zhu, 2002) under visual guidance using fluorescence and transmitted light illumination with two Axopatch-200B amplifiers (Molecular Devices). Cultured slices exhibit relatively high spontaneous activity comparable with intact brains (Zhu and Connors, 1999; Zhu, 2000). Thus, high calcium and magnesium bath solution $\left(29 \pm 1.5^{\circ} \mathrm{C}\right)$ containing (in $\left.\mathrm{mm}\right) 119 \mathrm{NaCl}, 2.5 \mathrm{KCl}, 4 \mathrm{CaCl}_{2}, 4 \mathrm{MgCl}_{2}, 26$ $\mathrm{NaHCO}_{3}, 1 \mathrm{NaH}_{2} \mathrm{PO}_{4}, 11$ glucose, 0.1 picrotoxin, and 0.002 2-chloroadenosine, $\mathrm{pH} 7.4$, was used to prevent epileptic activity after blocking inhibition. For acute slices, normal bath solution $\left(33 \pm 1.5^{\circ} \mathrm{C}\right)$ containing (in mM) $125 \mathrm{NaCl}, 2.5 \mathrm{KCl}, 2 \mathrm{CaCl}_{2}, 1 \mathrm{MgCl}_{2}, 25 \mathrm{NaHCO}_{3}$, $1.25 \mathrm{NaH}_{2} \mathrm{PO}_{4}, 11$ glucose, and 0.1 picrotoxin at $\mathrm{pH} 7.4$ was used ( $\mathrm{Zhu}$, 2000; Larkum and Zhu, 2002). The bath solutions were gassed with 5\% $\mathrm{CO}_{2} / 95 \% \mathrm{O}_{2}$. Patch recording pipettes (3-6 M $\Omega$ ) contained (in mM) 115 cesium methanesulfonate, $20 \mathrm{CsCl}, 10 \mathrm{HEPES}, 2.5 \mathrm{MgCl}_{2}, 4 \mathrm{Na}_{2} \mathrm{ATP}, 0.4$ $\mathrm{Na}_{3} \mathrm{GTP}, 10$ sodium phosphocreatine, 0.6 EGTA, and 0.1 spermine, $\mathrm{pH}$ 7.25. Synaptic responses were evoked by bipolar electrodes with single voltage pulses ( $200 \mu \mathrm{s}$, up to $20 \mathrm{~V}$ ) placed in hippocampal stratum radiatum or cortical layer $3 \sim 300 \mu \mathrm{m}$ away from the recorded hippocampal CA1 and cortical layer $2 / 3$ pyramidal cells. Synaptic AMPA responses at -60 and $+40 \mathrm{mV}$ were averaged over 90 trials and their ratio was used as an index of rectification. To minimize the effect from AMPA responses, the peak NMDA responses at $+40 \mathrm{mV}$ were measured after digital subtraction of estimated AMPA responses at $+40 \mathrm{mV}$. LTP was induced by a pairing protocol using 200 pulses at $2 \mathrm{~Hz}$ at $-5 \mathrm{mV}$ within 5 min after formation of the whole-cell configuration (Zhu et al., 2002; Qin et al., 2005). The responses were sampled at $0.2 \mathrm{~Hz}$ and averaged every 10 points. The amount of LTP was measured by averaging transmission $25 \mathrm{~min}$ after the LTP induction for $20 \mathrm{~min}$. All results are reported as mean \pm SEM and statistical differences of the means were determined using Wilcoxon and Mann-Whitney rank-sum nonparametric tests for paired and unpaired samples, respectively. The level of significance was set at $p \leq 0.05$.

\section{Results}

A number of previous studies, using high-frequency tetanus or theta-burst LTP-inducing stimuli and extracellular recording techniques, have examined synaptic plasticity in the hippocampal and cortical acute slices prepared from FMR1 knock-out and wild-type mice (Godfraind et al., 1996; Paradee et al., 1999; Li et al., 2002; Larson et al., 2005; Lauterborn et al., 2007). However, these studies disagree as to whether LTP is impaired in FMR1 knock-out mice, and whether the impairment is stimulation and/or age dependent. However, using a pairing or spike-timing 
A

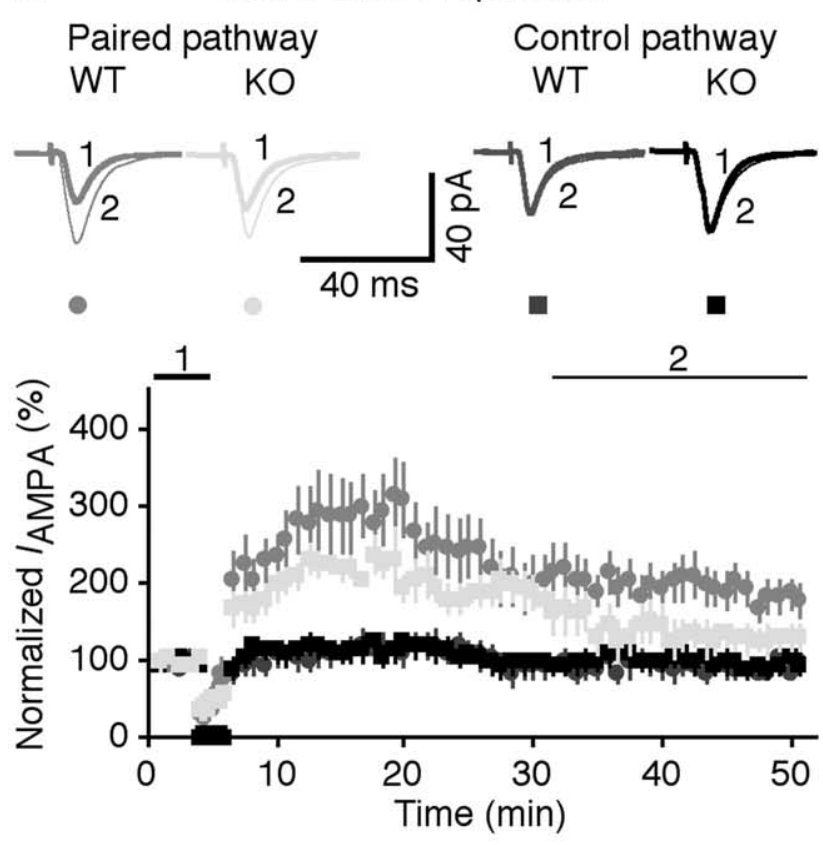

B

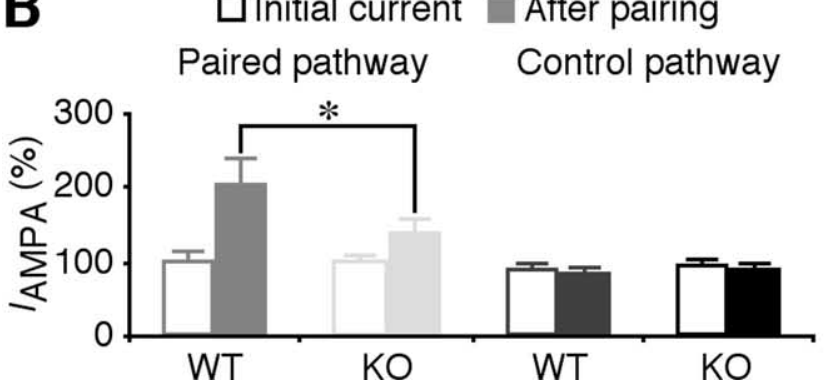

C

Culture Slice Preparation

Paired pathway
WT KO
Control pathway WT $\mathrm{KO}$
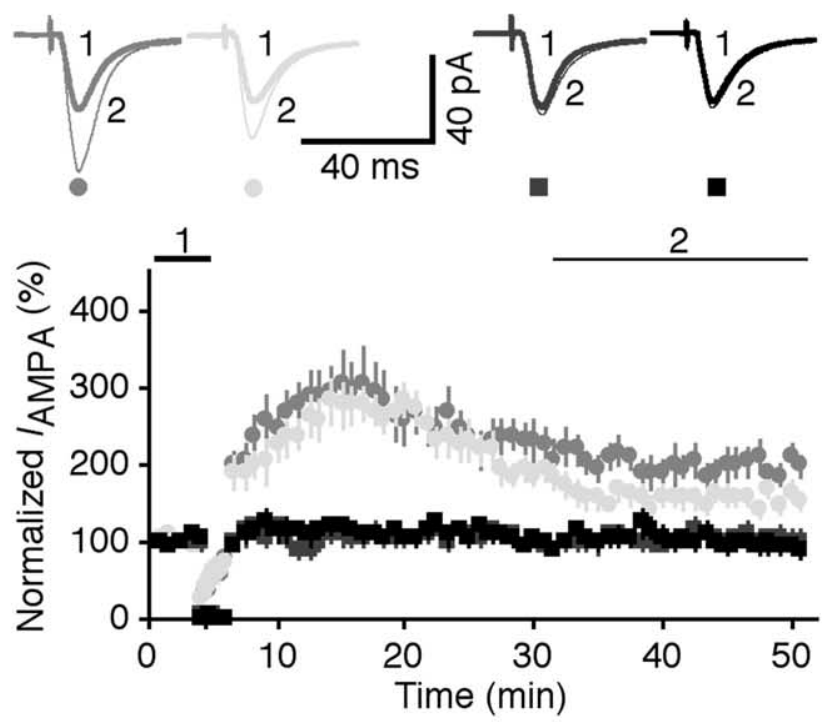

D

$\square$ Initial current

After pairing Paired pathway Control pathway

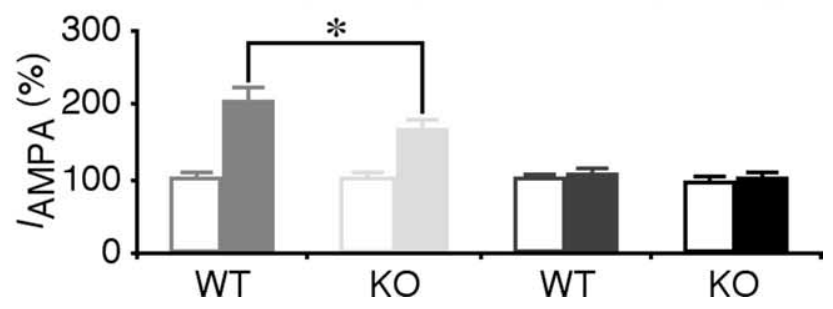

Figure 1. LTP is reduced in FMR1 KO mice. A, Average AMPA-R-mediated synaptic responses obtained before ( $-60 \mathrm{mV}$, thick trace) and after ( $-60 \mathrm{mV}$, thin trace) LTP-inducing pairing in paired (top left) and control pathways (top right) in hippocampal CA1 neurons in acute slices prepared from WT and FMR1 KO mice. Bottom plot, Normalized simultaneously evoked responses recorded from all CA1 neurons against time. $B$, Steady-state AMPA response amplitudes in paired (WT: $197.2 \pm 19.4 \%$ from initial $-25.0 \pm 3.5 \mathrm{pA}, n=19 ; \mathrm{KO}: 138.7 \pm 8.9 \%$ from initial $-32.4 \pm 3.1$ $\mathrm{pA}, n=22 ; p<0.05$ ) and control pathways (WT: $92.8 \pm 10.3 \%$ from initial $-22.1 \pm 2.9 \mathrm{pA}, n=19 ; \mathrm{K} 0: 99.7 \pm 9.4 \%$ from initial $-30.4 \pm 3.7 \mathrm{pA}, n=22 ; p=0.51$ ) in (A1 neurons from WT and KO mice before and after pairing. Note that the paired pathways had a significant potentiation after LTP induction compared with the control pathways in both WT $(n=19 ; p<0.005$; Wilcoxon test) and KO ( $n=22 ; p<0.005$; Wilcoxon test) mice. C, Average AMPA-R-mediated synaptic responses obtained before ( $-60 \mathrm{mV}$, thick trace) and after ( $-60 \mathrm{mV}$, thin trace) LTP-inducing pairing in paired (top left) and control pathway (top right) in hippocampal CA1 neurons in cultured slices prepared from WT and FMR1 KO mice. Bottom plot, Normalized simultaneously evoked responses recorded from all CA1 neurons against time. $D$, Steady-state AMPA response amplitudes in paired (WT:203.2 $\pm 12.8 \%$ from initial $-29.3 \pm 1.9 \mathrm{pA}, n=20 ; \mathrm{KO}: 157.6 \pm$ $6.7 \%$ from initial $-27.8 \pm 2.4 \mathrm{pA}, n=20 ; p<0.01$ ) and control pathways (WT: $102.2 \pm 7.8 \%$ from initial $-28.7 \pm 2.4 \mathrm{pA}, n=20 ; \mathrm{K} 0: 101.3 \pm 6.3 \%$ from initial $-26.2 \pm 2.2 \mathrm{pA}, n=20$; $p=0.97$ ) in CA1 neurons from WT and KO mice before and after pairing. Note that the paired pathways had a significant potentiation after LTP induction compared with the control pathways in both WT ( $n=20 ; p<0.005$; Wilcoxon test) and KO ( $n=20 ; p<0.005$; Wilcoxon test) mice. AMPA-R-mediated current amplitudes and SEs were normalized to average values of WT and K0 cells in paired pathways. ${ }^{*} p \leq 0.05$ (Mann-Whitney rank-sum nonparametric test).

LTP-inducing protocol, intracellular recordings have shown a complete loss of LTP in cortical neurons of FMR1 knock-out mice (Zhao et al., 2005; Meredith et al., 2007).

LTP is reduced in FMR1 knock-out mice

We wished to know whether and how Ras-dependent synaptic trafficking of AMPA-Rs is impaired in FMR1 knock-out mice. We first measured LTP in hippocampal CA1 pyramidal neurons using a whole-cell voltage-clamp technique, which isolates potentiated synaptic responses from other nonspecific effects [e.g., altered neuronal intrinsic properties (Zhang and Linden, 2003) and inhibitory transmission (Lei and McBain, 2004)]. We used the pairing protocol to induce maximal LTP in 2-week-old mice, at which developmental stage synaptic delivery of GluR2L- and GluR1-containing AMPA-Rs each contributes to $\sim 50 \%$ LTP
(Kolleker et al., 2003; Qin et al., 2005). In the acute slice preparation, CA1 neurons of both wild-type and FMR1 knock-out mice had LTP (Fig. 1A,B). However, LTP in FMR1 knock-out neurons was significantly smaller than that in wild-type neurons (Fig. $1 B$ ) (KO: $138.7 \pm 8.9 \%, n=22$; WT: $197.2 \pm 19.4 \%, n=$ $19 ; p<0.05)$. As controls, we examined AMPA and NMDA responses in FMR1 knock-out and wild-type neurons (Fig. 2). The input-output responses, ratio of AMPA and NMDA responses, as well as voltage-dependence of NMDAR responses were the same for FMR1 knock-out and wild-type neurons, consistent with previous reports (Godfraind et al., 1996; Huber et al., 2002; Zhao et al., 2005).

We wished to use a hippocampal cultured slice preparation, which has the advantage of molecular biology approaches, to dissect the molecular mechanism(s) underlying the defective LTP 

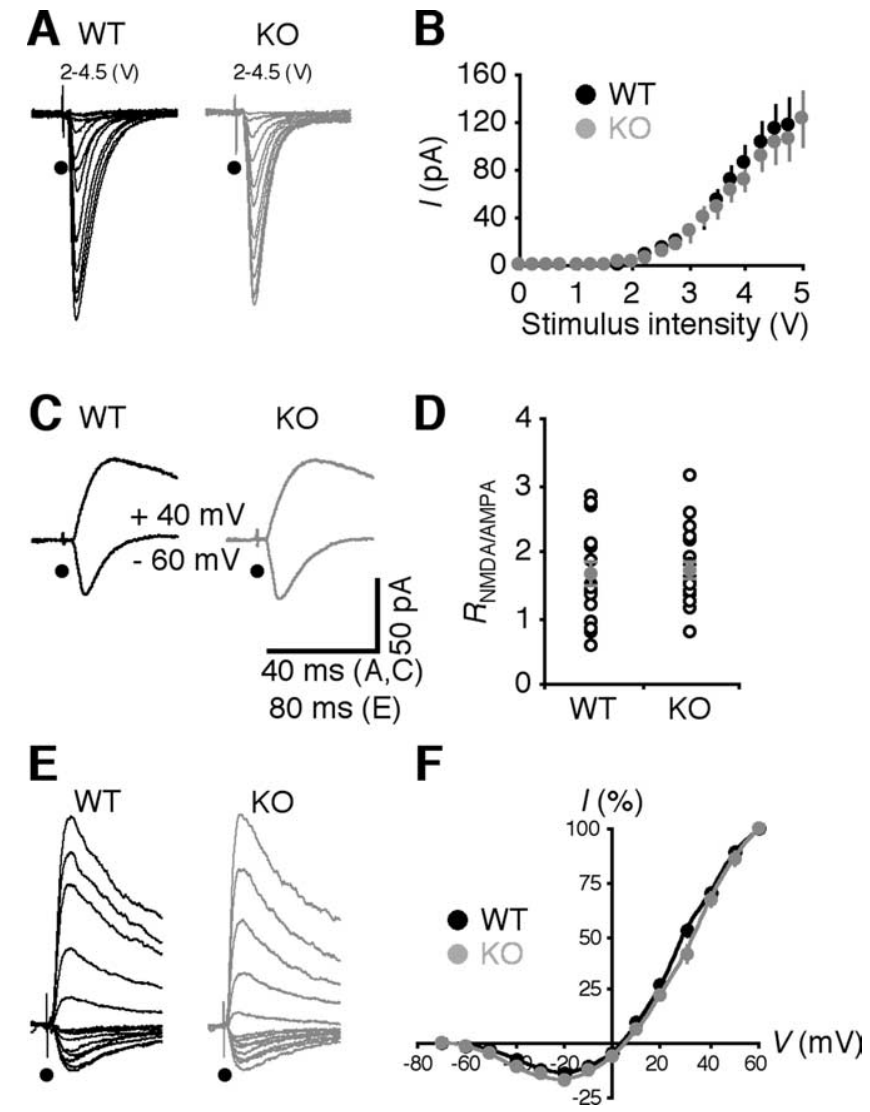

Figure 2. Synaptic responses in wild-type and FMR $1 \mathrm{KO}$ mice. A, Evoked AMPA-R-mediated responses from a WT neuron and an FMR1 K0 neuron at different stimulation intensities. $\boldsymbol{B}$, Plots of the average amplitudes of evoked AMPA responses against different stimulus intensities show no difference between WT $(n=24)$ and FMR1 KO $(n=20)$ neurons ( $p=0.80$; ANOVA). C, Evoked AMPA-R- $(-60 \mathrm{mV})$ and NMDA-R- $(+40 \mathrm{mV})$ mediated responses from a WT neuron and an FMR1 KO neuron. D, The ratio of NMDA and AMPA responses shows no significant difference between WT and FMR1 K0 neurons (WT: 1.62 $\pm 0.16, n=20 ; \mathrm{KO}: 1.69 \pm$ $0.32, n=20 ; p=0.60$; Mann-Whitney rank-sum nonparametric test). $\boldsymbol{E}$, Evoked NMDA-Rmediated responses from a WT neuron and an FMR1 KO neuron bathed in normal physiological solution containing additional $5 \mu \mathrm{m} \mathrm{DNQX}$ at different holding potentials (from $-70 \mathrm{mV}$ to $+50 \mathrm{mV}$ in $10 \mathrm{mV}$ steps). $\boldsymbol{F}$, Current-voltage ( $(-\eta)$ plot of average evoked NMDA responses (normalized to the responses at $+60 \mathrm{mV}$ ) against holding potentials shows no difference between WT $(n=20)$ and FMR1 KO $(n=16)$ neurons ( $p=0.83$; ANOVA).

in FMR1 knock-out mice. Thus, we reexamined LTP in cultured slices prepared from the hippocampus of FMR1 knock-out and wild-type mice (Fig. 1C,D). As with acute slices, FMR1 knock-out CA1 neurons in cultured slices had a reduced LTP compared with wild-type CA1 neurons (Fig. $1 D$ ) (KO: $157.6 \pm 6.7 \%, n=20$; WT: $203.2 \pm 12.8 \%, n=20 ; p<0.01)$. Together, these results indicate that LTP is reduced by $\sim 50 \%$ in CA1 neurons of FMR1 knock-out mice.

\section{Synaptic delivery of GluR1 is impaired in FMR1 knock-out mice}

AMPA-Rs with long cytoplasmic termini, including GluR1- and GluR2L-containing AMPA-Rs, are normally restricted from synapses and are driven into synapses by Ras signaling during activity-induced synaptic enhancement (Malinow and Malenka, 2002; Zhu et al., 2002; Qin et al., 2005). Spontaneous neural activity, such as occurs in cultured brain slices or intact brains of sleeping animals, stimulates Ras-MEK-ERK signaling, which is sufficient to induce GluR2L-mediated synaptic potentiation. In intact brains of awake animals, during which neuromodulator release is generally increased (Steriade and McCarley, 1990), neural activity stimulates additional Ras-PI3K-PKB signaling, which is required for GluR1-mediated synaptic potentiation. Because synaptic delivery of GluR2L- and GluR1-containing AMPA-Rs each contributes to $~ 50 \%$ of LTP in hippocampal CA1 neurons (Kolleker et al., 2003; Qin et al., 2005), we examined synaptic trafficking of GluR2L- and GluR1-containing AMPA-Rs in hippocampal cultured slices prepared from FMR1 knock-out and wild-type mice to determine whether a selective type of AMPA$\mathrm{R}$-mediated LTP is impaired in FMR1 knock-out mice. We first expressed a GFP-tagged pore mutant of GluR2L, GluR2L $(\mathrm{R} \rightarrow \mathrm{Q})-\mathrm{GFP}$, in CA1 neurons. In this construct, an $\mathrm{R} \rightarrow \mathrm{Q}$ mutation is generated at its pore region to make it a rectified channel, or electrophysiologically "tagged" (Kolleker et al., 2003). Because AMPA responses in pyramidal neurons are basically nonrectifying, the synaptic addition of rectified, recombinant GluR2L $(\mathrm{R} \rightarrow \mathrm{Q})$-GFP will be indicated by the enhanced amplitude and rectification of AMPA responses (Kolleker et al., 2003). We compared the evoked synaptic responses between GluR2L(R $\rightarrow$ Q)-GFP-expressing neurons, identified by GFP fluorescence (Zhu et al., 2000), and nearby nonexpressing neurons of FMR1 knock-out and wild-type mice. FMR1 knock-out and wild-type neurons expressing GluR2L $(\mathrm{R} \rightarrow \mathrm{Q})$-GFP had enhanced amplitude and rectification of AMPA responses compared with nonexpressing neurons (Fig. $2 A, B$ ), indicating synaptic delivery of GluR2L $(\mathrm{R} \rightarrow \mathrm{Q})-\mathrm{GFP}$. The enhancements in amplitude and rectification of AMPA responses were the same for FMR1 knock-out and wild-type neurons expressing GluR2L(R $\rightarrow$ Q)-GFP (Fig. 3A,B). Neuromodulators, such as histamine, stimulate more synaptic delivery of GluR2L (Qin et al., 2005). In the presence of histamine, FMR1 knock-out and wild-type neurons expressing GluR2L $(\mathrm{R} \rightarrow \mathrm{Q})$-GFP had the same enhanced rectification compared with nonexpressing neurons (Fig. $3 A, B$ ), indicating synaptic delivery of the same amount of rectified GluR2L $(\mathrm{R} \rightarrow \mathrm{Q})$-GFP in expressing FMR1 knock-out and wild-type neurons. In contrast to the nonhistamine condition, GluR2L(R $\rightarrow$ Q)-GFP expressing and nonexpressing neurons had AMPA responses with the same amplitude (Fig. $3 A, B$ ). These results suggest that histamine stimulates synaptic insertion of endogenous GluR2L and recombinant GluR2L(R $\rightarrow$ Q)-GFP in nonexpressing neurons and expressing neurons to a saturated level (cf. Qin et al., 2005; McCormack et al., 2006). Together, these results indicate that GluR2L-containing AMPA-Rs are delivered into synapses in FMR1 knock-out CA1 neurons to a similar level as in wild-type CA1 neurons.

To confirm that synaptic trafficking of endogenous GluR2Lcontaining AMPA-Rs is normal in FMR1 knock-out mice, we expressed the GFP-tagged cytoplasmic termini (ct) of GluR2L, GluR2Lct-GFP, in CA1 neurons in cultured slices of FMR1 knock-out mice. GluR2Lct-GFP acts as a dominant-negative construct and it selectively blocks synaptic trafficking of endogenous GluR2L-containing AMPA-Rs (Kolleker et al., 2003; Qin et al., 2005). Compared with nearby nonexpressing neurons, GluR2Lct-GFP-expressing neurons had depressed AMPA responses, with or without histamine included in culture media (Fig. 3C,D). NMDA responses were not different between GluR2Lct-GFP-expressing and -nonexpressing neurons (Fig. $3 C, D)$. Collectively, these results confirm that synaptic delivery of GluR2L-containing AMPA-Rs is normal in CA1 neurons of FMR1 knock-out mice.

We next asked whether GluR1-containing AMPA-Rs traffic into synapses of FMR1 knock-out mice. Spontaneous synaptic activity in cultured slices is not sufficient to drive GluR1- 

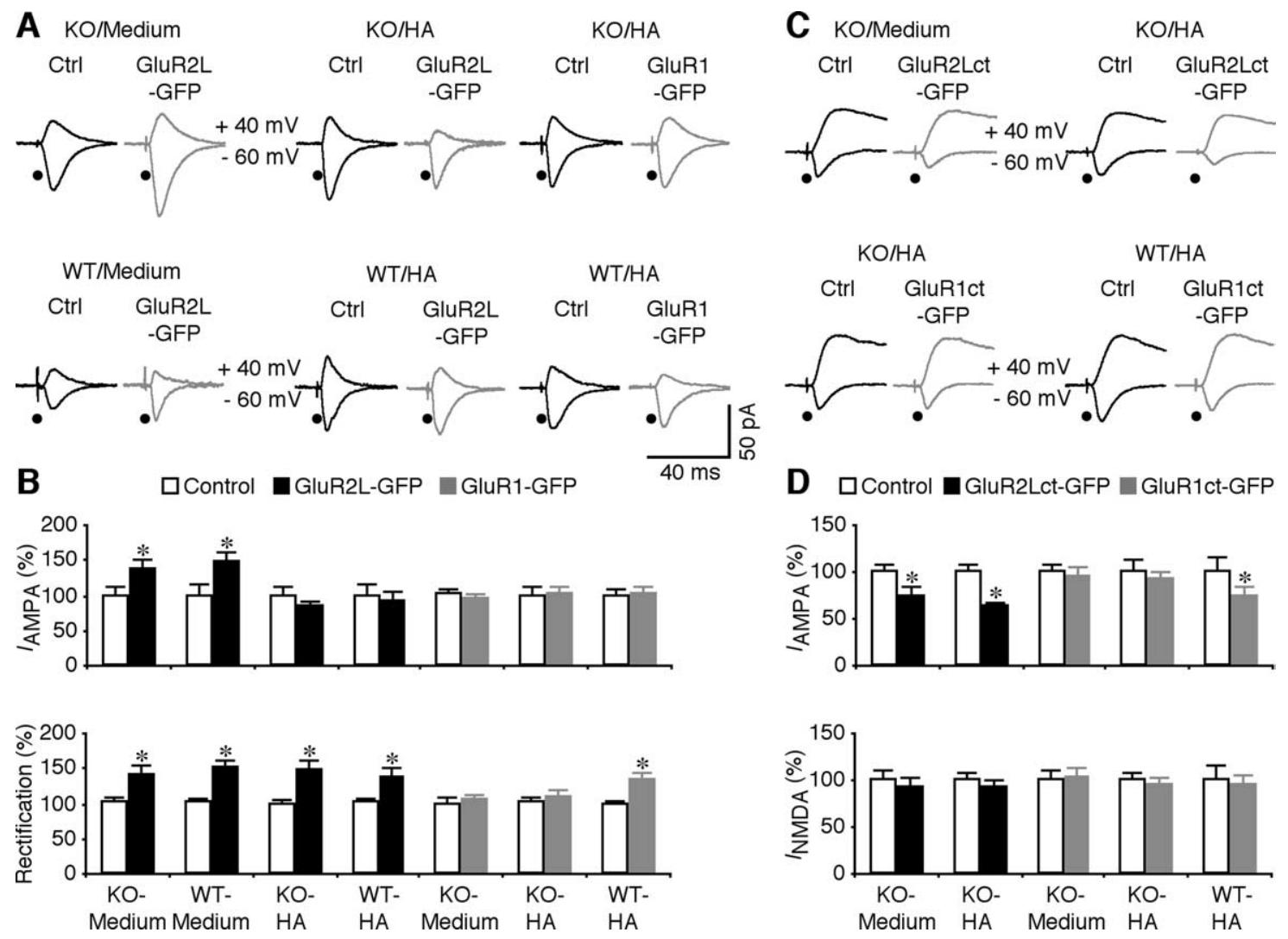

Figure 3. Synaptic delivery of GluR1 is impaired in FMR $1 \mathrm{KO}$ mice. $A$, Evoked AMPA-R-mediated responses recorded from nonexpressing (Ctrl) and GluR2L( $R \rightarrow Q$ )-GFP-expressing neurons from FMR1 K0 and WT mice cultured in normal media, in media with $75 \mu \mathrm{m}$ histamine (HA), and GluR1-GFP-expressing neurons from K0 or WT mice cultured in media with $75 \mu \mathrm{m} \mathrm{histamine.} B$, Top, AMPA responses in GluR2L $(\mathrm{R} \rightarrow \mathrm{Q})$-GFP-expressing (Exp) neurons from KO (Ctrl, $-35.2 \pm 4.2 \mathrm{pA} ; \operatorname{Exp},-48.6 \pm 4.4 \mathrm{pA} ; n=16 ; p<0.01)$ and WT (Ctrl, $-16.8 \pm 2.6 \mathrm{pA} ;$ Exp, $-24.7 \pm 3.0 \mathrm{pA} ; n=$ $19 ; p<0.05$ ) mice cultured in normal media, GluR2L( $R \rightarrow 0$ )-GFP-expressing neurons from KO (Ctrl, $-35.3 \pm 4.1 \mathrm{pA}$; Exp, $-29.2 \pm 2.8 \mathrm{pA} ; n=16 ; p=0.30)$ and WT (Ctrl, $-45.9 \pm 6.6 \mathrm{pA}$; Exp, $-42.6 \pm 5.9 \mathrm{pA} ; n=14 ; p=0.83$ ) mice cultured in media with histamine, GluR1-GFP-expressing neurons from K0 mice cultured in normal media (Ctrl, $-36.4 \pm 3.1 \mathrm{pA} ;$ Exp, $-34.1 \pm 3.4$ $\mathrm{pA} ; n=18 ; p=0.64)$, and GluR1-GFP-expressing neurons from KO (Ctrl, $-41.9 \pm 5.3 \mathrm{pA} ; \operatorname{Exp},-42.9 \pm 4.8 \mathrm{pA} ; n=20 ; p=0.65)$ and WT (Ctrl, $-37.3 \pm 3.5 \mathrm{pA} ; \mathrm{Exp},-37.7 \pm 4.4 \mathrm{pA} ; n=$ 19; $p=0.63$ ) mice cultured in media with histamine. Bottom, Rectification of GluR2L( $R \rightarrow Q)$-GFP-expressing neurons from K0 (Ctrl, 1.67 $\pm 0.17 ;$ Exp, 2.37 $\pm 0.22 ; n=16 ; p<0.05)$ and WT (Ctrl, $1.41 \pm 0.10 ; \operatorname{Exp}, 2.11 \pm 0.18 ; n=19 ; p<0.005)$ mice cultured in normal media, GluR2L ( $R \rightarrow 0)$-GFP-expressing neurons from KO (Ctrl, $1.74 \pm 0.11 ; \operatorname{Exp}, 2.60 \pm 0.24 ; n=16 ; p<0.005)$ and WT (Ctrl, 1.63 $\pm 0.10 ; \operatorname{Exp}, 2.26 \pm 0.17 ; n=14 ; p<0.005)$ mice cultured in media with histamine, GluR1-GFP-expressing neurons from K0 mice cultured in normal media (Ctrl, 1.75 $\pm 0.13 ;$ Exp, $1.81 \pm 0.15 ; n=18 ; p=0.93$ ), and GluR1-GFP-expressing neurons from K0 (Ctrl, 1.69 $\pm 0.14 ;$ Exp, $1.85 \pm 0.16 ; n=20 ; p=0.39$ ) and WT (Ctrl, 1.74 $\pm 0.09 ; \operatorname{Exp}, 2.39 \pm 0.17 ; n=19 ; p<$ $0.0005)$ mice cultured in media with histamine. Note that the relative increases in rectification were the same in GluR2L $(R \rightarrow 0)$-GFP-expressing neurons from K0 and WT neurons cultured in normal media (K0: $162.5 \pm 27.6 \%, n=16 ; \mathrm{WT}: 153.5 \pm 10.5 \% ; n=19 ; p=0.52$, Mann-Whitney rank-sum nonparametric test) and media with histamine (K0: $154.8 \pm 16.5 \%, n=14 ; \mathrm{WT}: 142.1 \pm$ $10.5 \% ; n=16 ; p=0.92$, Mann-Whitney rank-sum nonparametric test), but are significantly different in GluR1-GFP-expressing neurons from K0 and WT neurons cultured in media with histamine (KO: $113.0 \pm 7.4 \%, n=20 ; \mathrm{WT}: 140.0 \pm 10.0 \% ; n=19 ; p<0.05$, Mann-Whitney rank-sum nonparametric test). C, Evoked AMPA-R-mediated responses recorded from nonexpressing (Ctrl) and GluR2Lct-GFP-expressing neurons from FMR1 K0 mice cultured in normal media or in media with $75 \mu \mathrm{m}$ histamine, or GluR1ct-GFP-expressing neurons from K0 or WT mice cultured in media with $75 \mu$ m histamine. D, Top, AMPA responses in GluR2Lct-GFP-expressing neurons from K0 mice cultured in normal media (Ctrl, $-27.1 \pm 2.5 \mathrm{pA} ;$ Exp, $-19.9 \pm 3.2 \mathrm{pA} ; n=18 ; p<0.05$ ) and in media with histamine (Ctrl, $-28.7 \pm 2.5 \mathrm{pA}$; Exp, $-17.9 \pm 1.3 \mathrm{pA} ; n=18 ; p<0.005)$, GluR1ct-GFP-expressing neurons from K0 mice cultured in normal media (Ctrl, $-21.5 \pm 1.9 \mathrm{pA} ;$ Exp, $-20.5 \pm$ $1.9 \mathrm{pA} ; n=16 ; p=0.68)$, and GluR1ct-GFP-expressing neurons from KO (Ctrl, $-26.9 \pm 3.4 \mathrm{pA} ;$ Exp, $-24.8 \pm 2.3 \mathrm{pA} ; n=16 ; p=0.88)$ and WT (Ctrl, $-28.0 \pm 4.1 \mathrm{pA} ;$ Exp, $-20.4 \pm 3.1 \mathrm{pA}$; $n=16 ; p<0.05$ ) mice cultured in media with histamine. Bottom, NMDA responses in GluR2Lct-GFP-expressing neurons from K0 mice cultured in normal media (Ctrl, $51.3 \pm 5.4 \mathrm{pA}$; Exp, $47.4 \pm$ $4.9 \mathrm{pA} ; n=18 ; p=0.35$ ) and in media with histamine (Ctrl, $50.1 \pm 4.4 \mathrm{pA} ; \operatorname{Exp}, 46.6 \pm 3.3 \mathrm{pA} ; n=18 ; p=0.31)$, GluR1ct-GFP-expressing neurons from K0 mice cultured in normal media (Ctrl, $40.4 \pm 4.3 \mathrm{pA} ; \operatorname{Exp}, 41.9 \pm 3.5 \mathrm{pA} ; n=16 ; p=0.80)$, and GluR1ct-GFP-expressing neurons from KO (Ctrl, $49.1 \pm 4.0 \mathrm{pA} ;$ Exp, $46.2 \pm 4.7 \mathrm{pA} ; n=16 ; p=0.57)$ and WT (Ctrl, $50.3 \pm 7.5 \mathrm{pA} ; \operatorname{Exp}$, $47.2 \pm 5.5 \mathrm{pA} ; n=16 ; p=0.47$ ) mice cultured in media with histamine. AMPA-R- and NMDA-R-mediated current amplitudes, rectifications, and SEs were normalized to average values of control cells. ${ }^{*} p \leq 0.05$ (Wilcoxon test).

containing AMPA-Rs into synapses, but it does so in the presence of neuromodulators, such as histamine (Zhu et al., 2002; Qin et al., 2005). We expressed the GFP-tagged GluR1, GluR1-GFP, which is an "electrophysiologically-tagged" or rectified channel (Hayashi et al., 2000), in CA1 neurons in cultured slices. Neurons expressing GluR1-GFP had the same AMPA responses as nearby nonexpressing neurons of FMR1 knock-out mice, with or without histamine included in culture media (Fig. $3 A, B$ ). In contrast, in the presence of histamine, wild-type CA1 neurons expressing GluR1-GFP had enhanced rectification of AMPA responses compared with nearby nonexpressing neurons (Fig. 3A,B) (cf. Qin et al., 2005), indicating synaptic delivery of GluR1-GFP. These re- sults reveal that synaptic delivery of GluR1-GFP is compromised in CA1 neurons of FMR1 knock-out mice.

To confirm that synaptic delivery of endogenous GluR1containing AMPA-Rs is compromised in FMR1 knock-out mice, we examined the effects of expressing the GFP-tagged cytoplasmic termini of GluR1, GluR1ct-GFP, which acts as a dominantnegative construct and selectively blocks synaptic trafficking of endogenous GluR1-containing AMPA-Rs (Kolleker et al., 2003; Qin et al., 2005). GluR1ct-GFP-expressing neurons of FMR1 knock-out mice had the same AMPA and NMDA responses as nearby nonexpressing neurons, with or without histamine included in culture media (Fig. 3C,D). In the presence of histamine, 
A WT<smiles>CC1CCCC1C1CCC(C)C1C(F)F</smiles>

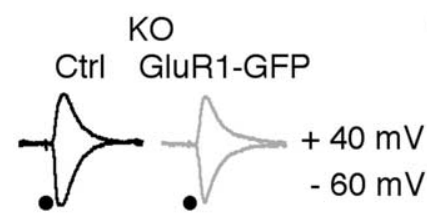

C WT Ctrl GluR1ct-GFP<smiles>CCCCCCCCC</smiles><smiles>CCCCC</smiles>

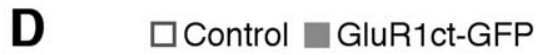

KO
口Control $\square$ GluR1-GFP

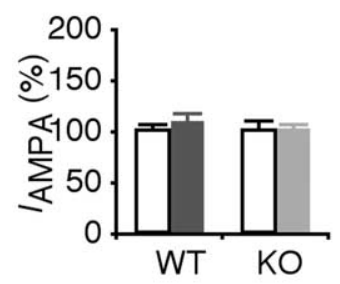

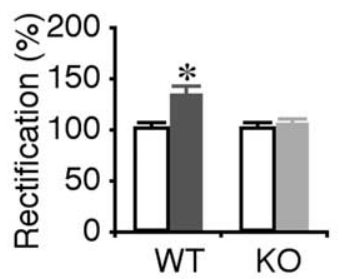

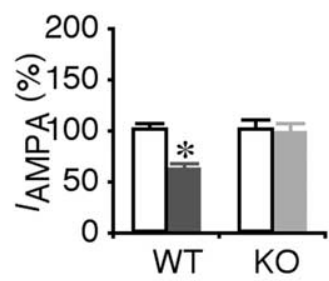

E WT Ctrl GluR4-GFP

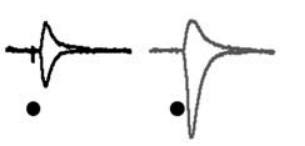

$\mathbf{F}$
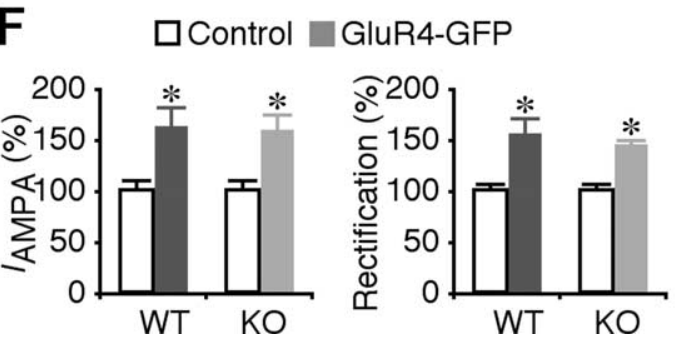

G WT Ctrl GluR4ct-GFP

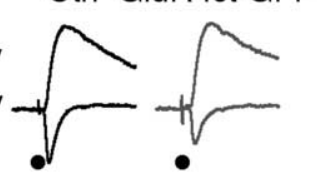

H

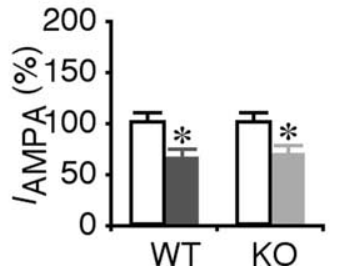

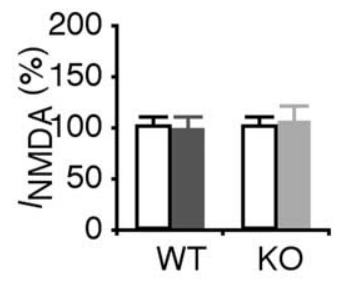
Ctrl GluR1ct-GFP

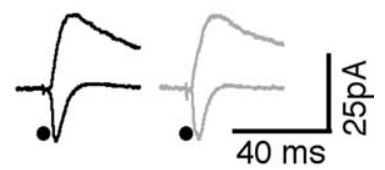

Figure 4. Synaptic delivery of GluR1 is deficient in cortical neurons of FMR1 K0 mice. A, Evoked AMPA-R-mediated responses recorded from nonexpressing (Ctrl) and GluR1-GFP-expressing neurons from WT and FMR1 K0 mice. $\boldsymbol{B}$, Left, AMPA responses in GluR1-GFP-expressing (Exp) neurons from WT (Ctrl, $-34.4 \pm 2.9 \mathrm{pA}$; Exp, $-36.8 \pm 3.8 \mathrm{pA} ; n=16 ; p=0.80)$ and K0 (Ctrl, $-36.9 \pm 4.5 \mathrm{pA} ; \operatorname{Exp},-37.1 \pm 3.0 \mathrm{pA} ; n=22 ; p=0.68)$ mice. Right, Rectification of GluR1-GFP-expressing neurons from WT (Ctrl, 1.38 $\pm 0.10 ;$ Exp, 1.80 $\pm 0.17 ; n=16 ; p<0.001)$ and K0 $(\mathrm{Ctrl}, 1.48 \pm 0.08 ;$ Exp, $1.52 \pm 0.10 ; n=22 ; p=0.99)$ mice. C, Evoked AMPA-R-and NMDA-R-mediated responses recorded from Ctrl and GluR1ct-GFP-expressing neurons from WT and FMR1 K0 mice. $D$, Left, AMPA responses in GluR1ct-GFP-expressing neurons from WT (Ctrl, $-42.9 \pm 3.7 \mathrm{pA}$; Exp, $-25.5 \pm 2.9 \mathrm{pA} ; n=16 ; p<0.05)$ and K0 (Ctrl, $-32.5 \pm 3.5 \mathrm{pA} ; \mathrm{Exp},-31.0 \pm 3.5 \mathrm{pA}$; $n=16 ; p=0.72$ ) mice. Right, NMDA responses in GluR1ct-GFP-expressing neurons from WT (Ctrl, $63.8 \pm 6.3$ pA; Exp, $61.0 \pm 8.6 \mathrm{pA} ; n=18 ; p=0.47)$ and K0 (Ctrl, $47.1 \pm 5.3 \mathrm{pA} ;$ Exp, $48.8 \pm$ $8.6 \mathrm{pA} ; n=18 ; p=0.82$ ) mice. $\boldsymbol{E}$, Evoked AMPA-R-mediated responses recorded from Ctrl and GluR4-GFP-expressing neurons from WT and FMR1 K0 mice. $\boldsymbol{F}$, Left, AMPA responses in GluR4-GFP-expressing neurons from WT (Ctrl, $-27.8 \pm 2.8$ pA; Exp, $-43.7 \pm 5.0 \mathrm{pA} ; n=18 ; p<0.01)$ and K0 (Ctrl, $-30.9 \pm 3.4$ pA; Exp, $-49.9 \pm 5.9 \mathrm{pA} ; n=16 ; p<0.05)$ mice. Right, Rectification of GluR4-GFP-expressing neurons from WT (Ctrl, $1.48 \pm 0.09 ;$ Exp, $2.12 \pm 0.31 ; n=18 ; p<0.001$ ) and K0 (Ctrl, $1.45 \pm 0.08 ;$ Exp, $2.23 \pm 0.25 ; n=16 ; p<0.001$ ) mice. G, Evoked AMPA-R- and NMDA-R-mediated responses recorded from Ctrl and GluR4ct-GFP-expressing neurons from WT and FMR1 K0 mice. $\boldsymbol{H}$, Left, AMPA responses in GluR4ct-GFP-expressing neurons from WT (Ctrl, $-46.8 \pm 4.3$ pA; Exp, $-30.5 \pm 4.4$ pA; $n=12 ; p<0.005)$ and KO (Ctrl, $-44.2 \pm 4.8$ pA; Exp, $-30.8 \pm 4.3$ pA; $n=14 ; p<0.05)$ mice. Right, NMDA responses in GluR4ct-GFPexpressing neurons from WT (Ctrl, 74.5 \pm 8.8 pA; Exp, 73.1 \pm 8.2 pA; $n=12 ; p=0.88)$ and K0 (Ctrl, 73.5 \pm 4.0 pA; Exp, 69.3 \pm 9.1 pA; $n=14 ; p=0.36)$ mice. AMPA-R-and NMDA-R-mediated current amplitudes, rectifications, and SEs were normalized to average values of control cells. ${ }^{*} p \leq 0.05$ (Wilcoxon test).

GluR1ct-GFP-expressing neurons of wild-type mice had reduced AMPA responses compared with nearby nonexpressing neurons (Fig. 3C,D) (cf. Qin et al., 2005), suggesting a blockade of synaptic delivery of endogenous GluR1 in GluR1ct-GFP-expressing neurons. Together, these results indicate that synaptic delivery of GluR1-containing AMPA-Rs is selectively impaired in CA1 neurons of FMR1 knock-out mice.

Is synaptic delivery of GluR1-containing AMPA-Rs impaired in other types of neurons of FMR1 knock-out mice? Previous studies have reported a complete loss of LTP at intracortical synapses in cortical layer 2/3 pyramidal neurons of FMR 1 knock-out mice (Zhao et al., 2005; Meredith et al., 2007). GluR1- and GluR4-containing AMPA-Rs are expressed in these neurons, and trafficking of these receptors mediates synaptic potentiation at intracortical synapses in these neurons (McCormack et al., 2006). Thus, we virally expressed GluR1-GFP in FMR1 knock-out and wild-type mice in vivo and subsequently examined their AMPA responses in an acute slice preparation (cf. McCormack et al., 2006). GluR1-GFP-expressing neurons from wild-type, but not FMR1 knock-out mice had enhanced rectification compared with nearby nonexpressing neurons (Fig. $4 A, B$ ), indicating that synaptic delivery of GluR1-GFP was impaired in layer $2 / 3$ pyramidal neurons of FMR1 knock-out mice. To confirm the impaired synaptic delivery of endogenous GluR1-containing AMPA-Rs in FMR1 knock-out mice, we virally expressed GluR1ct-GFP in layer 2/3 pyramidal neurons of FMR1 knock-out and wild-type mice in vivo and subsequently examined their AMPA and NMDA responses in vitro. Compared with nearby 
nonexpressing neurons, AMPA responses of GluR1ct-GFPexpressing neurons from wild-type, but not FMR1 knock-out mice, were depressed by $\sim 30 \%$ (Fig. $4 C, D$ ). NMDA responses were not different between GluR1ct-GFP expressing and nonexpressing neurons (Fig. 4C,D). These results indicate that synaptic delivery of GluR1-containing AMPA-Rs is impaired in cortical layer 2/3 pyramidal neurons of FMR1 knock-out mice.

As with GluR2L-containing AMPA-Rs, GluR4-containing AMPA-Rs are driven into synapses by spontaneous activity during synaptic potentiation (Zhu et al., 2002; Kolleker et al., 2003; McCormack et al., 2006). To examine whether synaptic trafficking of GluR4-containing AMPA-Rs is normal in FMR1 knockout mice, we virally expressed the GFP-tagged GluR4, GluR4GFP, in layer 2/3 pyramidal neurons of FMR1 knock-out and wild-type mice in vivo and then examined their AMPA responses in vitro (McCormack et al., 2006). GluR4-GFP-expressing neurons from FMR1 knock-out and wild-type mice had the same enhanced amplitude and rectification of AMPA responses (Fig. $4 E, F)$, indicating synaptic delivery of GluR4-GFP in both knockout and wild-type neurons. Expression of the GFP-tagged cytoplasmic termini of GluR4, GluR4ct-GFP, selectively blocks the trafficking of endogenous GluR4-containing AMPA-Rs (Zhu et al., 2002; Kolleker et al., 2003; McCormack et al., 2006). To confirm the normal synaptic trafficking of endogenous GluR4containing AMPA-Rs in FMR1 knock-out mice, we virally expressed GluR4ct-GFP in layer 2/3 pyramidal neurons of FMR1 knock-out and wild-type neurons in vivo and subsequently examined their AMPA and NMDA responses in vitro (McCormack et al., 2006). GluR4ct-GFP-expressing neurons from FMR1 knock-out and wild-type mice had the same depressed AMPA responses (Fig. 4G,H). NMDA responses were not different between GluR4ct-GFP expressing and nonexpressing neurons (Fig. $4 G, H)$. These results indicate that synaptic delivery of GluR4containing AMPA-Rs is normal in cortical layer 2/3 pyramidal neurons of FMR1 knock-out mice.

\section{Ras-PI3K-PKB signaling is compromised in FMR1 knock-out mice}

Strong Ras activity stimulates the MEK-ERK and PI3K-PKB pathways, and activation of both pathways is required for GluR1dependent LTP (Zhu et al., 2002; Qin et al., 2005). To determine whether Ras-MEK-ERK and Ras-PI3K-PKB signaling is normal in FMR1 knock-out mice, we first compared the levels of phosphorylated ERK and PKB in CA1 cells in cultured slices prepared from FMR1 knock-out and wild-type mice (Fig. 5A). Western blots showed that the levels of phosphorylated ERK1/2 and PKB were the same in CA1 cells of FMR1 knock-out and wild-type mice (Fig. $5 B, C$ ), suggesting that the basal Ras-MEK-ERK and Ras-PI3K-PKB activities were comparable between FMR1 knock-out and wild-type mice. Neuromodulators, such as histamine and acetylcholine, stimulate Ras-MEK-ERK and Ras$\mathrm{PI} 3 \mathrm{~K}-\mathrm{PKB}$ signaling via potentiation of NMDA responses in CA1 neurons (Bekkers, 1993; Mattingly and Macara, 1996; Murga et al., 1998; Qin et al., 2005). Histamine induced a significant increase in phosphorylation of ERK in CA1 cells from both FMR1 knock-out and wild-type mice, although the increase was somewhat smaller in knock-out mice. Notably, whereas histamine stimulated a significant increase in phosphorylation of PKB in wild-type CA1 cells, it had little effect on phosphorylation of $\mathrm{PKB}$ in FMR1 knock-out CA1 cells (Fig. 5B,C). Similarly, $\mathrm{McN}$, a selective muscarinic acetylcholine subtype $1(\mathrm{~m} 1)$ receptor agonist (Micheletti and Schiavone, 1990), stimulated phosphorylation of ERK in CA1 cells from both FMR1 knock-out and wild- type mice, but stimulated phosphorylation of PKB only in CA1 cells from wild-type mice (data not shown). These results suggest that, whereas the basal MEK-ERK and PI3K-PKB activity appears normal, the neuromodulator-stimulated PI3K-PKB signaling is severely impaired in FMR1 knock-out mice.

PI3K stimulates the production of phosphosphotidylinosital3,4,5-triphosphate $\left(\mathrm{PIP}_{3}\right)$, which brings $\mathrm{PDK} 1$ and $\mathrm{PKB}$ into proximity and facilitates phosphorylation of $\mathrm{PKB}$ by $\mathrm{PDK} 1$ (Manning and Cantley, 2007). Dependent on the cell type, PIP $_{3}$ may or may not stimulate PDK1 activity (Riojas et al., 2006). We found that the basal levels of phosphorylated PDK1 were slightly, although not significantly, higher in CA1 cells of FMR1 knockout mice compared with those of wild-type mice (Fig. 6). Histamine increased the levels of phosphorylated PDK1 in wild-type CA1 cells, but not in FMR1 knock-out CA1 cells (Fig. 6), consistent with the defective PI3K-PKB signaling in FMR1 knock-out mice. Together, these results indicate that the neuromodulatorstimulated Ras-MEK-ERK signaling is modestly altered, whereas the neuromodulator-stimulated Ras-PI3K-PKB signaling is considerably impaired in FMR1 knock-out mice. Because PI3K$\mathrm{PKB}$ signaling is crucial for synaptic delivery of GluR1containing AMPA-Rs (Qin et al., 2005) (see also Passafaro et al., 2001; Man et al., 2003), the prominent impairment of Ras-PI3K$\mathrm{PKB}$ signaling is consistent with the selective defect of histaminestimulated synaptic delivery of GluR1-containing AMPA-Rs in FMR1 knock-out mice (Fig. 3).

$\mathrm{PKA}$ and $\mathrm{PKC} / \mathrm{calcium}$-calmodulin-dependent protein kinase II (CaMKII) can phosphorylate S845 and S831 of GluR1 in vitro (Thomas and Huganir, 2004). However, at synapses in cultured slices and intact brains, CaMKII regulates Ras activity and, via the MEK-ERK and PI3K-PKB signaling pathways, controls phosphorylation of S845 and S831 of GluR1, respectively, which are the key steps leading to synaptic insertion of the receptor (Zhu et al., 2002; Thomas and Huganir, 2004; Qin et al., 2005). We wanted to further confirm the impairments of PI3K-PKB signaling and synaptic trafficking of GluR1 in fragile $\mathrm{X}$ cells in vivo given that the activities of Ras signaling and GluR1 trafficking in sleeping and awake animals are comparable with those in slices cultured in normal media and media with neuromodulators, respectively (Qin et al., 2005) (Fig. 5A). Western blot analysis showed that the levels of phosphorylated ERK, PKB, S845, and S831 of GluR1 were the same in CA1 cells of sleeping FMR1 knock-out and wild-type mice (Fig. $5 D, E$ ). In awake mice, the levels of phosphorylated ERK in CA1 cells of FMR1 knock-out mice were comparable with those of wild-type mice, whereas the levels of phosphorylated $\mathrm{PKB}$ were significantly reduced in CA1 cells of FMR1 knock-out mice (Fig. $5 F, G$ ), confirming the prominent deficit in Ras-PI3K-PKB signaling in FMR1 knock-out mice. Consistent with this idea, the levels of phosphorylated S845 of GluR1 were unchanged and those of phosphorylated S831 were reduced in CA1 cells of awake FMR1 knock-out mice (Fig. $5 F, G)$. Total GluR1 was not different between FMR1 knock-out and wild-type mice (Fig. $3 F, G$ ), consistent with previous reports (Zalfa et al., 2003; Giuffrida et al., 2005; Nosyreva and Huber, 2006) (but see Li et al., 2002). These results confirm that the impaired Ras-PI3K-PKB signaling underlies the selective defect of synaptic delivery of GluR1-containing AMPA-Rs in FMR1 knock-out mice (Fig. 3).

\section{Signal transduction through Ras is deficient in FMR1 knock-out mice}

To further explore where the defect observed in FMR1 knock-out mice lies within the Ras signal transduction pathways, we mea- 
A

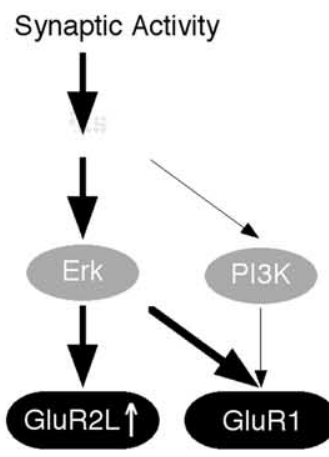

WT-No GluR1 Delivery
Culture Slices

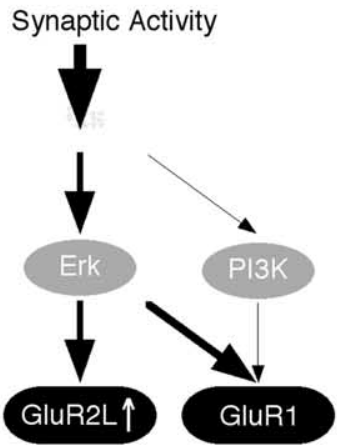

KO-No GluR1 Delivery
Culture Slices+HA/In Vivo Awake

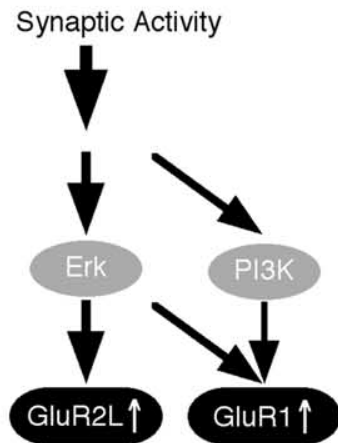

WT-GluR1 Delivery

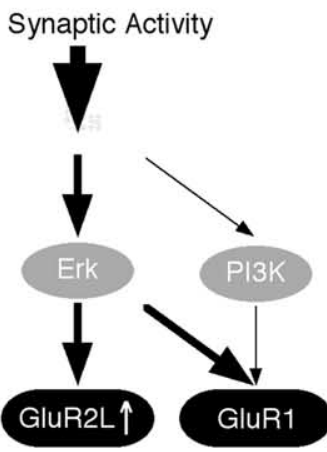

KO-No GluR1 Delivery

Culture Slice Preparation

B

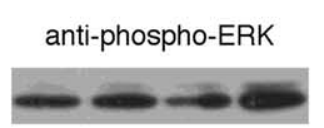

anti-ERK

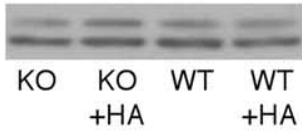

D

\section{anti-phospho-PKB}

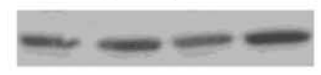

anti-PKB

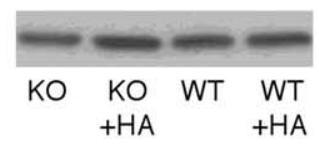

C

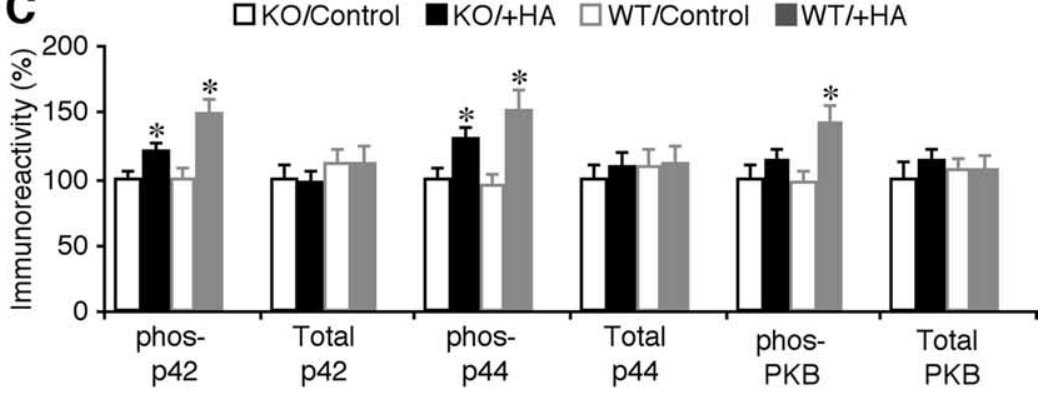

In vivo Preparation-Sleeping Mice

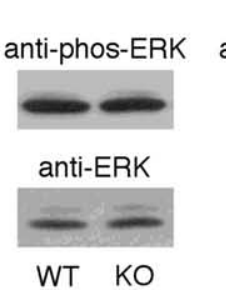

WT KO

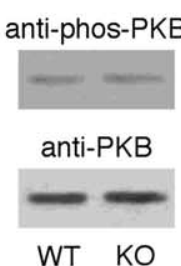

WT KO
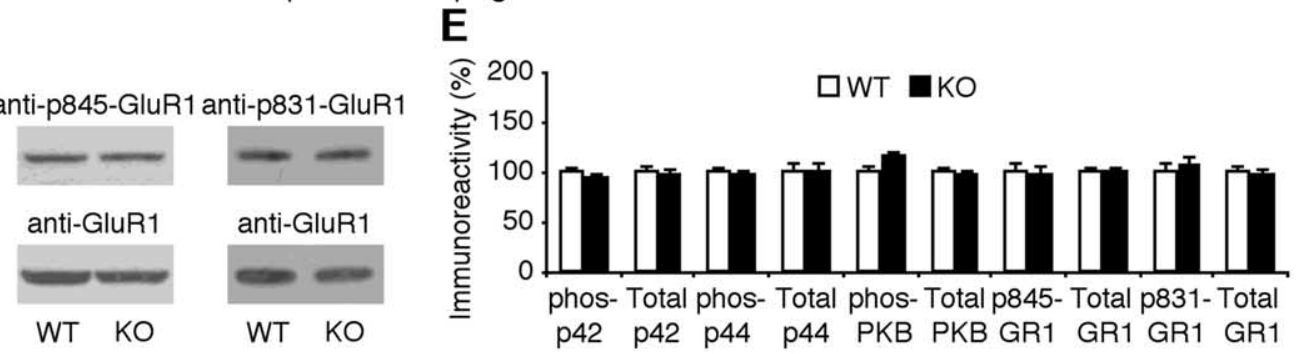

$\mathbf{F}$

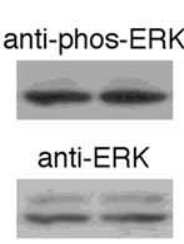

WT KO

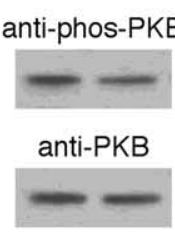

WT KO

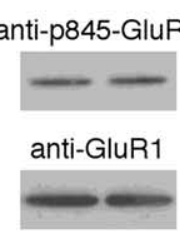

WT KO

In vivo Preparation-Awake Mice

G

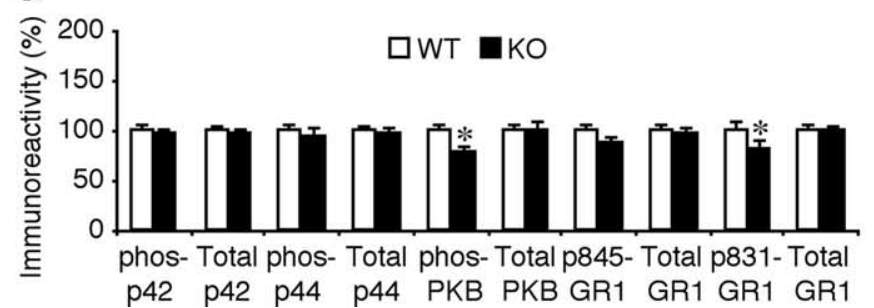

Figure 5. PI3K-PKB signaling is compromised in FMR1 KO mice. $A$, Schematic drawing shows MEK-ERK and PI3K-PKB signaling in FMR1 KO and WT mice. $B$, Western blots of phospho-ERK (left) and phospho-PKB (right) in hippocampal CA1 tissues of FMR1 KO and WT mice cultured in normal media or media containing $75 \mu \mathrm{m}$ histamine (HA). C, Relative amounts of phosphorylated (phos)-ERK (i.e., p42 and p44 bands) in CA1 cells from K0 [phos-p42: nonexpressing (Ctrl), $100.0 \pm 5.7 \%$; expressing (Exp), $119.4 \pm 7.1 \% ; n=16 ; p<0.005$; phos-p44: Ctrl, 100.0 $\pm 7.5 \%$; Exp, $128.9 \pm 9.1 \% ; n=16 ; p<0.005$ ] and WT (phos-p42: (trl, 99.3 \pm 8.2\%; Exp, 147.3 $\pm 11.6 \% ; n=16 ; p<0.01 ;$ phos-p44: (trl, $93.7 \pm 10.5 \%$; Exp, 149.5 $\pm 17.1 \% ; n=16 ; p<0.005$ ) mice cultured in media containing histamine. Relative amounts of total ERK (i.e., p42 and p44 bands) in CA1 cells from KO (p42: Ctrl, 100.0 \pm 10.9\%; Exp, 96.2 $\pm 10.4 \% ; n=16 ; p=0.55 ;$ p 44 : Ctrl, $100.0 \pm 11.2 \% ; \operatorname{Exp}, 107.5 \pm 13.2 \% ; n=16 ; p=0.61)$ and WT (p42: Ctrl, 111.1 $\pm 12.1 \% ; \operatorname{Exp}, 111.5 \pm 13.7 \% ; n=16 ; p=0.30 ; p 44: \operatorname{Ctrl}, 107.5 \pm 14.3 \% ; \operatorname{Exp}, 110.8 \pm 13.8 \% ; n=16 ; p=$ 0.93) mice cultured in media containing histamine are shown. Relative amounts of phos-PKB in CA1 cells from KO (Ctrl, $100.0 \pm 10.2 \%$; Exp, 112.9 $\pm 10.3 \% ; n=12 ; p=0.48$ ) and WT (Ctrl, $95.8 \pm$ 9.4\%; Exp, $140.9 \pm 13.3 \% ; n=12 ; p<0.005$ ) mice cultured in media containing histamine are shown. Relative amounts of total PKB in CA1 cells from KO (Ctrl, $100.0 \pm 12.5 \%$; Exp, $111.9 \pm$ $11.5 \% ; n=12 ; p=0.06)$ and WT (Ctrl, 106.8 $\pm 9.1 \% ;$ Exp, 105.2 $\pm 13.6 \% ; n=12 ; p=0.88)$ mice cultured in media containing histamine are shown. Note that phos-ERK ( $n=16 ;$ phos-p42, $p=0.78$; phos-p44, $p=0.92)$, total ERK $(n=16 ; p 42, p=0.45 ; p 44, p=0.42)$, phos-PKB $(n=12 ; p=0.94)$, and total PKB $(n=12 ; p=0.64)$ did not differ between hippocampal CA1 tissues from K0 and WT mice cultured in normal media. D, Western blots of phos-ERK, phos-PKB, phos-p845-GluR1, and phos-p831-GluR1 in hippocampal CA1 tissue prepared from sleeping WT and FMR1 KO mice. $\boldsymbol{E}$, Relative amounts of phos-ERK (phos-p42: WT, $100.0 \pm 3.9 \%$; KO, $93.6 \pm 3.3 \% ; n=15 ; p=0.18$; phos-p44: WT, $100.0 \pm 7.6 \%$; (Figure legend continues.) 
A

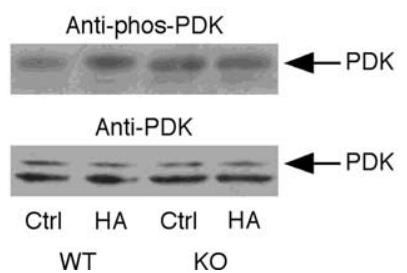

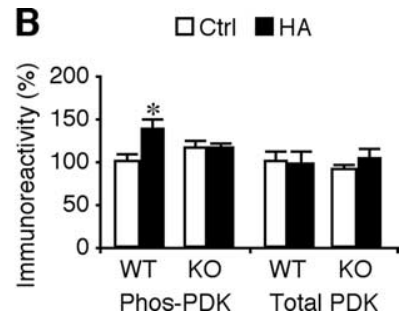

Figure 6. PDK signal transduction is altered in FMR1 KO mice. A, Blots of phosphorylated PDK (phos-PDK) and total PDK in CA1 tissues of WT and FMR1 KO mice cultured in normal media (Ctrl) or media containing $75 \mu \mathrm{m}$ histamine (HA). B, Relative amounts of phosphorylated PDK (WT mice: Ctrl, $100.0 \pm 9.4 \% ; \mathrm{HA}, 138.8 \pm 10.0 \% ; n=12 ; p<0.05 ; \mathrm{KO}$ mice: Ctrl, $116.5 \pm 7.9 \%$; K0, $114.1 \pm 8.0 \% ; n=12 ; p=0.31$ ) and total PDK (WT mice: Ctrl, $100.0 \pm 13.0 \%$; HA, $98.0 \pm 13.8 \% ; n=12 ; p=0.94 ; \mathrm{KO}$ mice: $\mathrm{Ctrl}, 89.2 \pm 7.1 \% ; \mathrm{HA}: 106.6 \pm 12.7 \% ; n=12$; $p=0.31)$ in CA1 tissues prepared from WT and KO mice. The relative values and SEs were normalized to average amounts of phos-PDK or total PDK from CA1 cells from wild-type mice. ${ }^{*} p \leq 0.05$ (Wilcoxon test).

sured the levels of the active form of Ras (GTP-bound Ras) in FMR1 knock-out and wild-type mice (Fig. 7A). Interestingly, the Ras-GTP levels in CA1 tissues of cultured slices prepared from FMR1 knock-out were higher than those of wild-type mice (Fig. $7 B, C)$. Histamine stimulated the Ras-GTP levels in both FMR1 knock-out and wild-type mice, but the enhancement of Ras-GTP levels was smaller in FMR1 knock-out CA1 cells than wild-type CA1 cells (Fig. 7 B, C). The total amounts of Ras were the same in all conditions (Fig. $7 B, C$ ). The same results were obtained when the muscarinic agonist $\mathrm{McN}$ was used as the neuromodulator agonist (data not shown). Because the Ras activity in CA1 cells depends on behavioral states (Qin et al., 2005), to confirm the aberrant Ras activity in FMR1 knock-out mice in vivo, we further examined the Ras-GTP levels in CA1 cells prepared from sleeping and awake animals (Fig. 7D,E). Consistent with the in vitro results, in the sleeping animals, FMR1 knock-out CA1 cells had significantly higher Ras-GTP levels than wild-type CA1 neurons. In the awake animals, the Ras-GTP levels were increased in both FMR1 knock-out and wild-type CA1 cells. The enhancement of Ras-GTP level was smaller in FMR1 knock-out cells than wildtype cells. The total amounts of Ras were the same in CA1 cells of

$\leftarrow$

(Figure legend continued.) K0, $96.1 \pm 6.9 \% ; n=15 ; p=0.41$ ) and total ERK (p42: WT, $100.0 \pm 3.4 \% ; \mathrm{KO}, 95.8 \pm 3.6 \% ; n=15 ; p=0.16 ; \mathrm{p} 44: \mathrm{WT}, 100.0 \pm 9.5 \% ; \mathrm{K} 0,99.7 \pm$ $10.8 \% ; n=15 ; p=0.80$ ) in CA1 cells. Relative amounts of phos-PKB (WT, $100.0 \pm 6.3 \%$; KO, $115.5 \pm 4.1 \% ; n=15 ; p=0.16)$ and total PKB (WT, $100.0 \pm 2.3 \% ; \mathrm{KO}, 97.8 \pm 2.5 \% ; n=15$; $p=0.33$ ) in CA1 cells are shown. Relative amounts of phos-p845-GluR1 (WT, $100.0 \pm 9.9 \%$; K0, $96.6 \pm 9.8 \% ; n=12 ; p=0.72$ ) and total GluR1 (WT, $100.0 \pm 3.6 \% ; \mathrm{KO}, 98.9 \pm 4.7 \%$; $n=12 ; p=0.75$ ) in CA1 cells are shown. Relative amounts of phos-p831-GluR1 (WT, $100.0 \pm$ $8.6 \% ; \mathrm{KO}, 106.3 \pm 9.1 \% ; n=15 ; p=0.21$ ) and total GluR1 (WT, $100.0 \pm 7.6 \% ; \mathrm{KO}, 95.5 \pm$ $9.0 \% ; n=15 ; p=0.36$ ) in (A1 cells are shown. $\boldsymbol{F}$, Western blots of phos-ERK, phos-PKB, phos-p845-GluR1, and phos-p831-GluR1 in hippocampal CA1 tissue prepared from awake WT and FMR1 KO mice. G, Relative amounts of phos-ERK (phos-p42: WT, $100.0 \pm 4.8 \% ; \mathrm{KO}, 96.9 \pm$ $3.3 \% ; n=13 ; p=0.51 ;$ phos-p44: WT, $100.0 \pm 7.7 \% ; \mathrm{K} 0,93.7 \pm 10.9 \% ; n=13 ; p=0.55)$ and total ERK (p42: WT, $100.0 \pm 3.0 \% ; \mathrm{KO}, 98.1 \pm 3.4 \% ; n=13 ; p=0.81 ; \mathrm{p} 44:$ WT, $100.0 \pm$ $3.7 \% ; \mathrm{K} 0,97.7 \pm 4.2 \% ; n=13 ; p=0.78$ ) in CA1 cells. Relative amounts of phos-PKB (WT, $100.0 \pm 7.8 \% ; \mathrm{KO}, 76.7 \pm 8.9 \% ; n=12 ; p<0.05)$ and total PKB (WT, $100.0 \pm 6.6 \% ; \mathrm{KO}$, $99.7 \pm 8.4 \% ; n=12 ; p=0.98$ ) in (A1 cells are shown. Relative amounts of phos-p845-GluR1 (WT, $100.0 \pm 6.3 \% ; \mathrm{K} 0,88.1 \pm 7.0 \% ; n=12 ; p=0.25$ ) and total GluR1 (WT, $100.0 \pm 6.4 \%$; $\mathrm{K} 0,95.4 \pm 9.2 \% ; n=12 ; p=0.94)$ in (A1 cells are shown. Relative amounts of phos-p831GluR1 (WT, 100.0 $\pm 8.3 \% ; \mathrm{K} 0,81.4 \pm 9.2 \% ; n=13 ; p<0.05$ ) and total GluR1 (WT, $100.0 \pm$ $5.7 \% ; \mathrm{KO}, 99.3 \pm 5.4 \% ; n=13 ; p=0.70)$ in CA1 cells are shown. Each lane was loaded with the same amount of protein $(40$ or $60 \mu \mathrm{g})$. The relative values and SEs were normalized to average amounts of phos-ERK, phos-PKB, phos-p845-GluR1, phos-p831-GluR1, total ERK, PKB, or GluR1 from CA1 cells from wild-type mice. ${ }^{*} p \leq 0.05$ (Wilcoxon test). sleeping and awake FMR1 knock-out and wild-type mice. Together, these results suggest that the basal Ras activity, although upregulated, can be somewhat further stimulated by neuromodulators and increased vigilance (or the awake state). Because MEK-ERK signaling seems to be mostly normal, whereas PI3KPKB signaling is reduced in FMR1 knock-out mice (Fig. 4), the upregulated Ras activity indicates that the signal transduction between Ras and MEK-ERK is modestly reduced, whereas that between Ras and PI3K-PKB is more severely impaired.

Expression of CaMKII, the upstream activator of Ras (Zhu et al., 2002), is enhanced in FMR1 knock-out mice (Zalfa et al., 2003; Hou et al., 2006). To determine whether the upregulated basal Ras activity is caused by the enhanced CaMKII expression, we included in the culture media either additional $10 \mathrm{mM} \mathrm{Mg}^{2+}$, which blocks spontaneous synaptic activity (Zhu et al., 2000), or $3 \mu \mathrm{M}$ 1-[NO-bis-1,5-isoquinolinesulfonyl]- $N$-methyl-L-tyrosyl4-phenylpiperazine (KN-62), a CaMKII inhibitor. High $\mathrm{Mg}^{2+}$ or KN-62 reduced the Ras-GTP levels by $\sim 50 \%$ in CA1 cells of wild-type and FMR1 knock-out mice (Fig. $7 F-I$ ), indicating that about half of Ras activity is dependent on synaptic activity and CaMKII activity in wild-type and FMR1 knock-out mice. These results suggest that the increased CaMKII protein expression accounts in part for the elevated basal Ras activity in FMR1 knockout mice.

The upregulated basal Ras activity, combined with the unchanged MEK-ERK and decreased PI3K-PKB signaling outputs, indicates inefficiencies of Ras in relaying the signal from upstream to downstream components, and particularly in propagating the signal to the PI3K-PKB pathway in FMR1 knock-out mice. To further confirm this point, we coexpressed a truncated constitutively active form of CaMKII, tCaMKII, with GluR1-GFP using a vector containing an IRES, GluR1-GFP-IRES-tCaMKII, in CA1 neurons in cultured slices prepared from FMR1 knockout mice. This construct stimulates Ras signaling and drives synaptic delivery of GluR1 in wild-type animals (Hayashi et al., 2000; Zhu et al., 2002). GluR1-GFP-IRES-tCaMKII expressing CA1 neurons of FMR1 knock-out mice had enhanced AMPA responses, but no change in rectification (Fig. $8 A, B$ ), indicating that the potentiation was caused by synaptic delivery of AMPA-Rs other than GluR1-GFP, presumably endogenous GluR2L-containing AMPA-Rs (Zhu et al., 2002; Qin et al., 2005). These results suggest that enhancing signaling upstream of Ras does not effectively stimulate PI3K-PKB signaling and synaptic delivery of GluR1-containing AMPA-Rs in FMR1 knock-out mice.

We wished to know whether the downstream pathways of Ras are intact in FMR1 knock-out mice. We expressed two GFPtagged constitutively active Ras mutants in CA1 neurons in cultured slices prepared from FMR1 knock-out mice: one was $\operatorname{Ras}(\mathrm{G} 12 \rightarrow \mathrm{V}, \mathrm{E} 37 \rightarrow \mathrm{G})$, called Ras(G37)-GFP, and the other was Ras $(\mathrm{G} 12 \rightarrow \mathrm{V}$, Y40 $\rightarrow$ C), called Ras(C40)-GFP. These two constructs drive synaptic delivery of GluR2L- and GluR1-containing AMPA-Rs via constitutively stimulating Ras-MEK-ERK and Ras-PI3K-PKB signaling, respectively (Qin et al., 2005). Both Ras(G37)-GFP- and Ras(C40)-GFP-expressing neurons of FMR1 knock-out mice had significantly enhanced AMPA responses (Fig. 8A,B). As a control, neurons expressing a GFPtagged constitutively active Ras mutant Ras $(\mathrm{G} 12 \rightarrow \mathrm{V}, \mathrm{T} 35 \rightarrow \mathrm{S})$, called Ras(S35)-GFP, which does not stimulate synaptic delivery of AMPA-Rs in CA1 neurons (Qin et al., 2005), had the same AMPA responses compared with nearby nonexpressing neurons of FMR1 knock-out mice (Fig. $8 A, B$ ). These results demonstrate that the downstream MEK-ERK and PI3K-PKB pathways are 
A

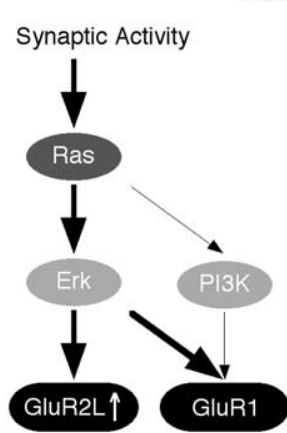

WT-No GluR1 Delivery
Culture Slices

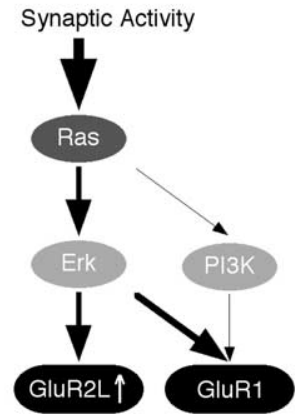

KO-No GluR1 Delivery
Culture Slices+HA/In Vivo Awake

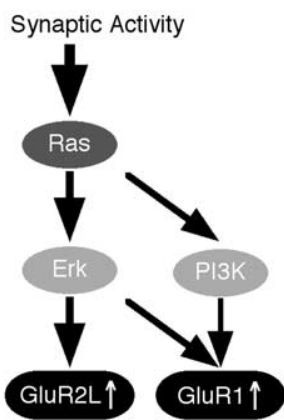

WT-GluR1 Delivery

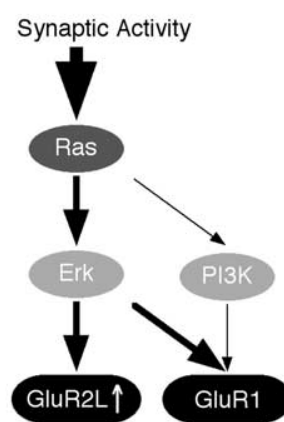

KO-No GluR1 Delivery
Culture Slice Preparation
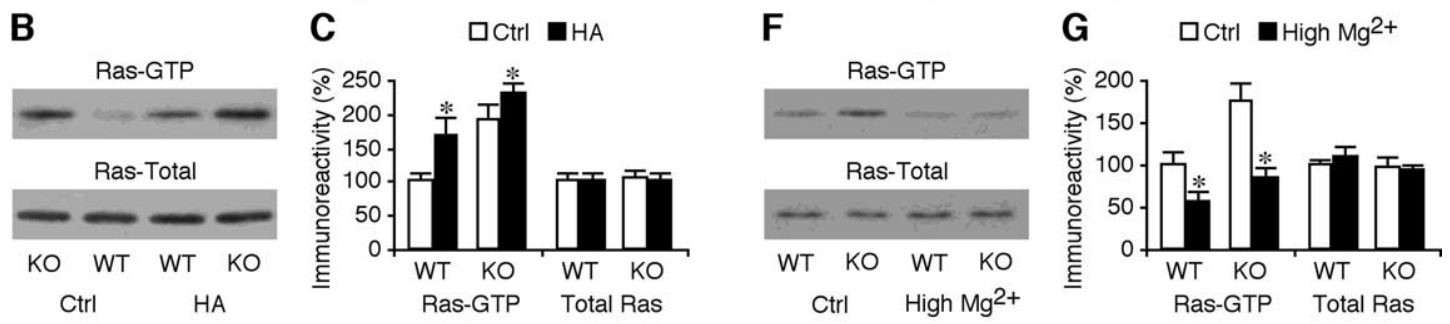

In Vivo Preparation
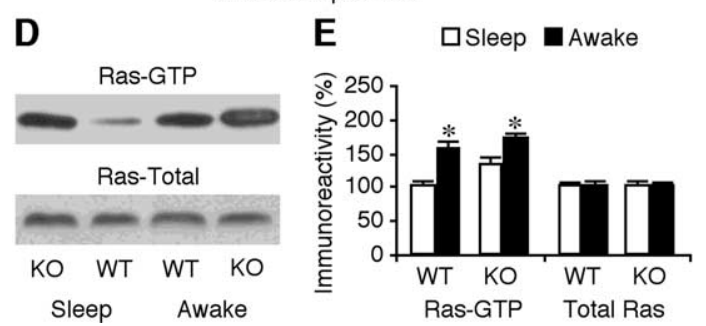

Culture Slice Preparation

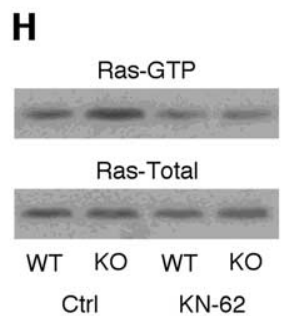

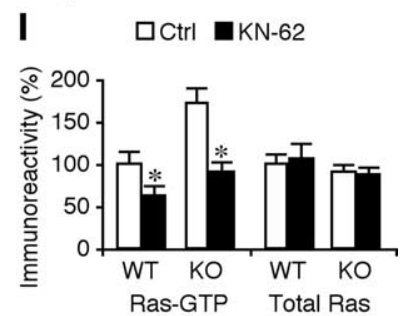

Figure 7. Ras activity is upregulated in FMR1 KO mice. $\boldsymbol{A}$, Schematic drawing shows Ras-MEK-ERK and Ras-PI3K-PKB signaling in FMR1 K0 and WT mice. $\boldsymbol{B}$, Blots of GTP-bound Ras and total Ras in CA1 tissues of FMR1 K0 and WT mice cultured in normal media (Ctrl) or media containing $75 \mu \mathrm{m}$ histamine (HA). C, Relative amounts of Ras-GTP (WT mice: Ctrl, $100.0 \pm 15.2 \%$; HA, $166.0 \pm$ 30.4\%; $n=10 ; p<0.01 ; \mathrm{KO}$ mice: Ctrl, 191.2 $\pm 22.3 \% ; \mathrm{HA}, 228.8 \pm 16.7 \% ; n=10 ; p<0.05$ ) and total Ras (Ctrl, 100.0 $\pm 12.0 \% ; H A, 100.6 \pm 13.5 \% ; n=10 ; p=0.96$ for WT mice; KO mice: $\mathrm{Ctrl}, 106.8 \pm 9.7 \% ; \mathrm{HA}, 103.5 \pm 10.1 \% ; n=10 ; p=0.33)$ in CA1 tissues prepared from WT and K0 mice. Note that HA enhanced levels of Ras-GTP in CA1 cells prepared from both K0 ( $n=10 ; p<$ $0.05)$ and WT $(n=10 ; p<0.01)$ mice. D, Blots of GTP-bound Ras and total Ras in CA1 tissues of sleeping and awake FMR1 K0 and WT mice. E, Relative amounts of Ras-GTP (WT mice: Sleep, $100.0 \pm$ 9.9\%; Awake, $155.8 \pm 13.5 \% ; n=12 ; p<0.005 ;$ K0 mice: Sleep, $133.0 \pm 11.7 \%$; Awake, $170.5 \pm 10.7 \% ; n=12 ; p=0.05$ ) and total Ras (WT mice: Sleep, 100.0 \pm 5.8\%; Awake, 101.6 \pm 6.1\%; $n=12 ; p=0.88 ; \mathrm{KO}$ mice: Sleep, $102.4 \pm 5.4 \%$; Awake, $102.0 \pm 4.8 \% ; n=12 ; p=0.97)$ in CA1 tissues prepared from WT and K0 mice. Note that CA1 cells had enhanced levels of Ras-GTP in awake animals compared with sleeping animals in both K0 $(n=12 ; p=0.05)$ and WT $(n=12 ; p<0.05)$ mice. F, Blots of GTP-bound Ras and total Ras in CA1 tissues of FMR1 K0 and WT mice cultured in normal media or media containing additional $10 \mathrm{~mm} \mathrm{Mg}^{2+}$. G, Relative amounts of Ras-GTP (WT mice: Ctrl, $100.0 \pm 16.7 \% ; \mathrm{Mg}{ }^{2+}, 56.3 \pm 11.7 \% ; n=12 ; p<0.05 ; \mathrm{KO}$ mice: Ctrl, $173.6 \pm 23.2 \% ; \mathrm{Mg}^{2+}, 83.8 \pm 14.0 \% ; n=12 ; p<0.05$ ) and total Ras (WT mice: Ctrl, $100.0 \pm 6.8 \% ; \mathrm{Mg}^{2+}, 108.2 \pm 12.8 \% ; n=12 ; p=0.53 ; \mathrm{K} 0 \mathrm{mice}: \mathrm{Ctrl}, 96.3 \pm 13.2 \% ; \mathrm{Mg}{ }^{2+}, 92.9 \pm$ $8.4 \% ; n=12 ; p=0.88$ ) in CA1 tissues prepared from WT and K0 mice. $\boldsymbol{H}$, Blots of GTP-bound Ras and total Ras in CA1 tissues of WT and FMR1 K0 mice cultured in normal media or media containing in $3 \mu \mathrm{m} \mathrm{KN}-62$ (KN). I, Relative amounts of Ras-GTP (WT mice: Ctrl, 100.0 $\pm 16.2 \%$; KN, $63.7 \pm 10.9 \% ; n=12 ; p<0.01 ; \mathrm{K} 0$ mice: Ctrl, $179.6 \pm 18.6 \%$; KN, $89.4 \pm 12.2 \% ; n=12 ; p<0.005$ ) and total Ras (WT mice: Ctrl, 100.0 $\pm 14.0 \% ; \mathrm{KN}, 105.6 \pm 19.5 \% ; n=12 ; p=0.99 ; \mathrm{KO}$ mice: (trl, $90.5 \pm 10.8 \% ; \mathrm{KN}, 86.4 \pm 11.9 \% ; n=12 ; p=0.64$ ) in (A1 tissues prepared from WT and K0 mice. For each set of cell lysates, $35 \mu \mathrm{g}$ of protein was used to purify and blot GTP-bound Ras and $7.5 \mu \mathrm{g}$ of protein was used to directly blot total Ras. The relative values and SEs were normalized to average amounts of Ras-GTP or total Ras of CA1 cells from control WT tissues or sleeping WT mice. ${ }^{*} p \leq 0.05$ (Wilcoxon test).

mainly intact and exogenously expressed active Ras can signal through the pathways and rescue synaptic GluR1 trafficking in FMR1 knock-out mice.

\section{Enhancing Ras-PI3K-PKB signaling restores synaptic} plasticity in FMR1 knock-out mice

Based on our findings that endogenous Ras is inefficient in relaying signal from upstream to downstream, in particular to the PI3K-PKB pathway to control synaptic GluR1 trafficking, whereas exogenously expressed active Ras drives GluR1 into synapses in FMR1 knock-out mice, we reasoned that it may be possible to restore normal synaptic delivery of GluR1-containing
AMPA-Rs and LTP in these mice by enhancing Ras signaling or by reducing the activation threshold for PI3K-PKB (Fig. 9A). To test these ideas, we first examined whether overexpression of wild-type Ras could potentiate responses of Ras to upstream stimuli (i.e., synaptic and CaMKII activities) and restore synaptic delivery of GluR1-containing AMPA-Rs in FMR1 knock-out mice. We linked GluR1-GFP- and the RFP-tagged wild-type form of Ras, Ras(wt)-RFP, using IRES, and then expressed this construct, GluR1-GFP-IRES-Ras(wt)-RFP, in CA1 neurons of FMR1 knock-out mice. Neurons expressing GluR1-GFP-IRESRas(wt)-RFP had the same AMPA responses as nearby nonexpressing neurons cultured in normal media (Fig. 9B, C). In the 

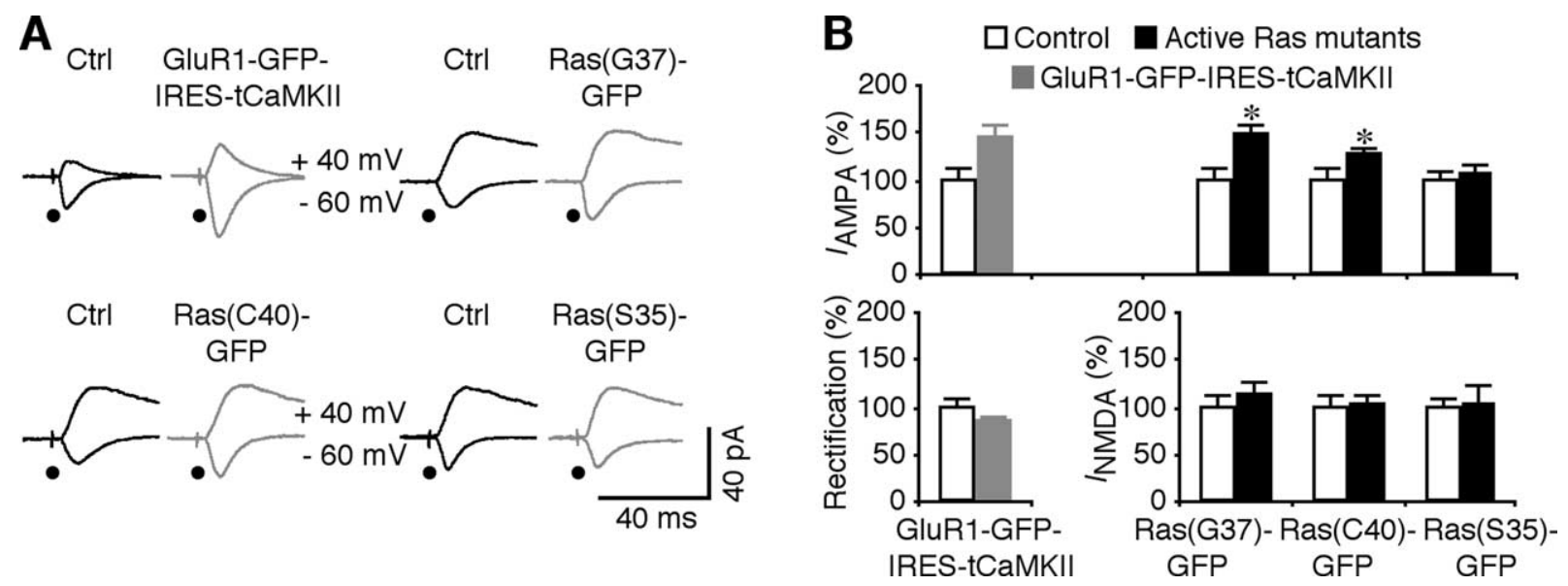

Figure 8. Downstream Ras signaling pathways are functional in FMR1 KO mice. A, Evoked AMPA-R- and NMDA-R-mediated responses recorded from nonexpressing (Ctrl) and GluR1-GFP-IREStCaMKII, Ras(G37)-GFP, Ras(C40)-GFP, and Ras(S35)-GFP-expressing (Exp) neurons from FMR1 KO mice. B, Top, AMPA responses in GluR1-GFP-IRES-tCaMKII-expressing (Ctrl, - 22.6 \pm 1.9 pA; Exp, $-32.9 \pm 2.9 \mathrm{pA} ; n=14 ; p<0.01)$, $\operatorname{Ras}(\mathrm{G} 37)$-GFP-expressing (Ctrl, $-24.1 \pm 3.0 \mathrm{pA} ; \operatorname{Exp},-35.2 \pm 3.8 \mathrm{pA} ; n=16 ; p<0.05), \operatorname{Ras}((40)$-GFP-expressing (Ctrl, $-39.2 \pm 3.5 \mathrm{pA} ;$ Exp, $-49.8 \pm$ $3.6 \mathrm{pA} ; n=20 ; p<0.001)$, and Ras(S35)-GFP-expressing (Ctrl, $-26.7 \pm 2.6 \mathrm{pA} ;$ Exp, $-28.6 \pm 3.7 \mathrm{pA} ; n=16 ; p=0.76$ ) expressing neurons from FMR1 K0 mice. Bottom, Rectification of GluR1-GFP-IRES-tCaMKII-expressing (Ctrl, $2.07 \pm 0.19 ;$ Exp, $1.74 \pm 0.07 ; n=14 ; p=0.09)$, NMDA responses in Ras(G37)-GFP-expressing (Ctrl, $38.3 \pm 5.1 \mathrm{pA} ; \mathrm{Exp}, 42.7 \pm 5.0 \mathrm{pA} ; n=16 ; p=$ 0.54), Ras(C40)-GFP-expressing (Ctrl, $62.0 \pm 6.9 \mathrm{pA} ;$ Exp, 64.1 $\pm 6.1 \mathrm{pA} ; n=20 ; p=0.74)$, and Ras(S35)-GFP-expressing (Ctrl, $44.2 \pm 3.6 \mathrm{pA} ; \operatorname{Exp}, 45.7 \pm 8.8 \mathrm{pA} ; n=16 ; p=0.50)$ neurons from FMR1 K0 mice. AMPA-R- and NMDA-R-mediated current amplitudes, rectifications, and SEs were normalized to average values of control cells. ${ }^{*} p \leq 0.05$ (Wilcoxon test).

presence of histamine in culture media, GluR1-GFP-IRESRas(wt)-RFP-expressing neurons had enhanced amplitude and rectification of AMPA responses (Fig. 9B, C), indicating synaptic delivery of GluR1-GFP. These results indicate that overexpressing wild-type Ras restores the histamine-stimulated synaptic delivery of GluR1-GFP in FMR1 knock-out mice.

We wished to confirm the idea that enhancing Ras-PI3KPKB signaling restores synaptic delivery of GluR1-containing AMPA-Rs using an independent approach. Phosphatase and tensin homolog deleted on chromosome 10 (PTEN) negatively regulates $\mathrm{PI} 3 \mathrm{~K}-\mathrm{PKB}$ signaling by dephosphorylating $\mathrm{PIP}_{3}$ (Maehama and Dixon, 1998; Sun et al., 1999). Therefore, expressing a dominant-negative form of PTEN is expected to reduce the threshold for activation of PI3K-PKB signaling and may restore synaptic delivery of GluR1 (Fig. 9A). We tested this idea by coexpressing GluR1-GFP with an RFP-tagged dominant-negative form of PTEN $(\mathrm{C124} \rightarrow \mathrm{S}$ ) (Sun et al., 1999), PTEN(dn)-RFP, in CA1 neurons of FMR1 knock-out mice. Neurons coexpressing GluR1-GFP and PTEN(dn)-RFP had the same AMPA responses as nearby nonexpressing neurons cultured in normal media, whereas in the presence of histamine, neurons coexpressing GluR1-GFP and PTEN(dn)-RFP had enhanced amplitude and rectification of AMPA responses (Fig. 9B,C), indicating synaptic delivery of GluR1-GFP. Including $10 \mu \mathrm{M}$ 2-(4-morpholinyl)-8phenyl-4H-1-benzopyran-4-one (LY294002), a PI3K inhibitor, in culture media blocked the histamine-stimulated enhancement of rectification and amplitude of AMPA responses in neurons coexpressing GluR1-GFP and PTEN(dn)-RFP (Fig. 9B, C), confirming the requirement of PI3K activity. These results indicate that reducing the threshold for activation of PI3K-PKB signaling restores synaptic delivery of GluR1-GFP in FMR1 knock-out mice.

To determine whether restoration of synaptic delivery of GluR1-containing AMPA-Rs works in vivo, we virally expressed GluR1-GFP-IRES-Ras(wt)-RFP in hippocampal CA1 neurons in intact brains of FMR1 knock-out mice. During expression of the construct, the animals were awake, which was required for synaptic delivery of GluR1 (Qin et al., 2005). After $\sim 16$ h of expression, acute hippocampal slices were made from these animals and
AMPA responses were recorded and compared between GluR1GFP-IRES-Ras(wt)-RFP-expressing and nearby nonexpressing CA1 neurons. Neurons expressing GluR1-GFP-IRES-Ras(wt)RFP had increased amplitude and rectification compared with nearby nonexpressing neurons (Fig. 9B,C), indicating synaptic insertion of GluR1-GFP in expressing neurons. As a control, expression of GluR1-GFP alone in awake FMR1 knock-out mice resulted in no synaptic delivery of the receptor because GluR1GFP-expressing neurons had the same AMPA responses compared with nearby nonexpressing neurons (Fig. 9B,C). Together, these results suggest that enhancing signal transduction from Ras to PI3K-PKB restores synaptic delivery of GluR1-containing AMPA-Rs in FMR1 knock-out mice.

To determine whether restoration of synaptic delivery of GluR1-containing AMPA-Rs enhances LTP in FMR1 knock-out mice, we measured LTP in GluR1-GFP-IRES-Ras(wt)-RFPexpressing CA1 neurons in cultured slices prepared from FMR1 knock-out mice. GluR1-GFP-IRES-Ras(wt)-RFP-expressing neurons had enhanced LTP compared with nearby nonexpressing neurons (Fig. 10 A,B) (expressing, $184.4 \pm 21.3 \%$; control, $148.0 \pm 12.9 \% ; n=14 ; p<0.05)$. The magnitude of LTP in GluR1-GFP-IRES-Ras(wt)-RFP-expressing neurons of FMR1 knock-out mice was comparable with that of wild-type mice (compare Fig. 1). The enhanced LTP in GluR1-GFP-IRESRas(wt)-RFP-expressing neurons was accompanied by an increase in rectification of AMPA responses compared with nearby nonexpressing neurons, indicating synaptic insertion of GluR1GFP during LTP. A control experiment showed that FMR1 knock-out CA1 neurons expressing GluR1-GFP alone exhibited neither enhanced LTP $(144.9 \pm 10.6 \% ; n=12)$ nor larger rectification after LTP (Fig. $10 A, B$ ). These results indicate that enhancing wild-type Ras signaling restores normal LTP in CA1 neurons of FMR1 knock-out mice by driving synaptic delivery of GluR1-containing AMPA-Rs.

To confirm that expression of wild-type Ras enhances LTP via stimulating PI3K-PKB signaling, we measured LTP in FMR1 knock-out CA1 neurons expressing Ras(wt)-GFP with or without the PI3K inhibitor LY294002 (Fig. 10C,D). We found that Ras(wt)-GFP-expressing neurons of FMR1 knock-out mice had 
enhanced LTP compared with nearby nonexpressing neurons (Fig. 7C,D) (expressing, $174.0 \pm 12.8 \%$; control, $137.5 \pm$ $8.4 \% ; n=18 ; p<0.01)$. In the presence of LY294002 in the bath solution, Ras(wt)GFP-expressing neurons of FMR1 knockout mice had the same LTP as nonexpressing neurons (Fig. 10C,D) (expressing, $139.1 \pm 18.9 \%$; control, $137.2 \pm 15.8 \%$; $n=18 ; p=0.91)$, indicating the requirement of PI3K activity for the Ras(wt)GFP-potentiated LTP. Collectively, these results suggest that facilitating Ras or its downstream PI3K-PKB signaling restores normal synaptic delivery of GluR1containing AMPA-Rs and LTP in FMR1 knock-out mice.

\section{Discussion}

In this study, we demonstrated that hippocampal LTP is considerably reduced in FMR1 knock-out mice because of prominent impairments of synaptic delivery of GluR1-containing AMPA-Rs and transduction of Ras signaling downstream to the PI3K-PKB pathway. Enhancing the signal transduction from Ras to PI3KPKB restores synaptic delivery of GluR1containing AMPA-Rs and normal LTP in FMR1 knock-out mice. These results suggest that either genetic and/or pharmacological enhancement of Ras-PI3K signaling may be a potential therapeutic approach to alleviate the cognitive disorders of patients with fragile $\mathrm{X}$ syndrome.

\section{Altered synaptic plasticity and learning in FMR1 knock-out mice}

Here, we report a selective defect of synaptic delivery of GluR1- but not GluR2L- and GluR4-containing AMPA-Rs. The partial alteration of synaptic plasticity in knockout mice is expected because the fragile $\mathrm{X}$ syndrome is accompanied by moderate mental deficits (Paradee et al., 1999; Loesch et al., 2004; Skinner et al., 2005). Moreover, our findings are in concert with recent reports of reduced surface expression of GluR1 in FMR1 knock-out and FMRP knockdown neurons (Nosyreva and $\mathrm{Hu}-$ ber, 2006; Nakamoto et al., 2007), although the majority of surface GluR1containing AMPA-Rs measured in those studies are likely to be extrasynaptic (Zamanillo et al., 1999). Finally, both GluR1- and GluR4-containing AMPA-Rs mediate synaptic transmission and potentiation in cortical neurons (McCormack et al., 2006). However, only GluR1-containing AMPARs, but not GluR4-containing AMPA-Rs, participate in the potentiation induced by classic LTP-inducing stimuli (our unpublished data). Thus, selective impairment of synaptic trafficking of GluR1- but not GluR4-containing AMPA-Rs at intracortical synapses explains both the complete loss of LTP and apparently normal postnatal growth of transmission at these syn-
A

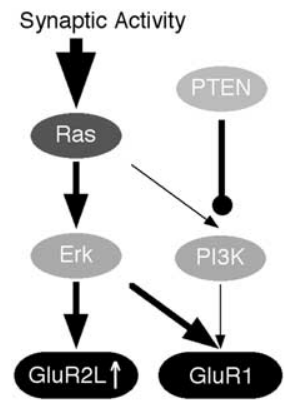

KO-No GluR1 Delivery
Culture Slices+HA/In Vivo Awake

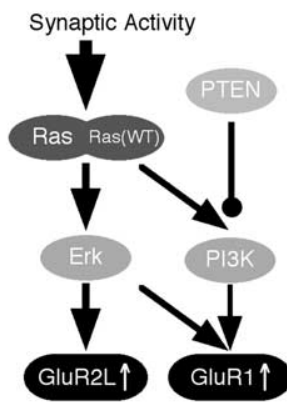

KO-GluR1 Delivery

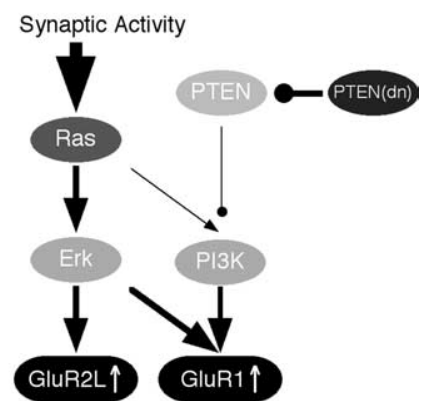

KO-GluR1 Delivery

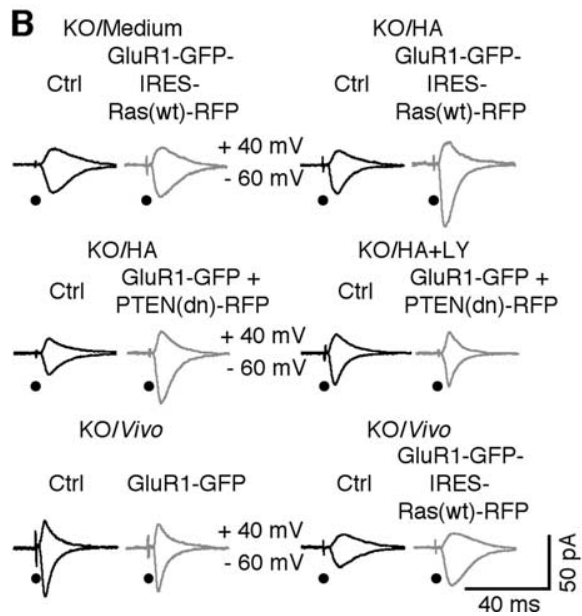

Figure 9. Enhancing Ras-PI3K-PKB signaling restores normal GluR1 trafficking in FMR1 K0 mice. $A$, Schematic drawing shows rescue of Ras-PI3K-PKB signaling in FMR1 KO mice with the wild-type form of Ras or a dominant-negative form of PTEN. $\boldsymbol{B}$, Evoked AMPA-R-mediated responses recorded from nonexpressing (Ctrl) and GluR1-GFP-IRES-Ras(wt)-RFP-expressing CA1 neurons, CA1 neurons coexpressing GluR1-GFP and PTEN(dn)-RFP from FMR1 K0 mice cultured in media with $75 \mu \mathrm{m}$ histamine (HA), or media with $75 \mu \mathrm{m} \mathrm{HA}$ and $10 \mu \mathrm{m}$ LY294002, and GluR1-GFP- and GluR1-GFP-IRES-Ras(wt)-RFP-expressing CA1 neurons from awake FMR1 KO mice. C, Top, AMPA responses in GluR1-GFP-IRES-Ras(wt)-RFP-expressing (Exp) neurons from K0 mice cultured in normal media (Ctrl, $-24.8 \pm 2.7 \mathrm{pA} ;$ Exp, $-27.9 \pm 4.6 \mathrm{pA} ; n=16 ; p=0.96)$ and in media with histamine (Ctrl, $-21.0 \pm$ $3.0 \mathrm{pA} ;$ Exp, $-32.9 \pm 4.6 \mathrm{pA} ; n=14 ; p<0.01)$; neurons coexpressing GluR1-GFP and PTEN(dn)-RFP from K0 mice cultured in normal media (Ctrl, $-33.8 \pm 4.4 \mathrm{pA}$; Exp, $-38.1 \pm 3.4 \mathrm{pA} ; n=14 ; p=0.47)$, in media with histamine (Ctrl, $-28.6 \pm 4.6 \mathrm{pA}$; $\operatorname{Exp},-44.6 \pm 5.5 \mathrm{pA} ; n=12 ; p<0.05)$, and in media with histamine and $10 \mu \mathrm{M} \mathrm{LY} 294002$ (Ctrl, $-27.7 \pm 3.7 \mathrm{pA}$; Exp, $-27.5 \pm 3.7 \mathrm{pA} ; n=18 ; p=0.81$ ); GluR1-GFP-expressing CA1 neurons from awake KO (Ctrl, $-27.9 \pm 3.5 \mathrm{pA} ; \mathrm{Exp},-25.6 \pm$ $3.0 \mathrm{pA} ; n=16 ; p=0.61$ ) and WT (Ctrl, $-27.1 \pm 3.7 \mathrm{pA} ; \operatorname{Exp},-28.6 \pm 2.7 \mathrm{pA} ; n=16 ; p=0.37$ ) mice; and GluR1-GFP-IRESRas(wt)-RFP-expressing (Ctrl, $-34.7 \pm 4.3 \mathrm{pA} ;$ Exp, $-49.9 \pm 5.5 \mathrm{pA} ; n=12 ; p<0.005)$ CA1 neurons from awake K0 mice. Bottom, Rectification of GluR1-GFP-IRES-Ras(wt)-RFP-expressing (Exp) neurons from K0 mice cultured in normal media (Ctrl, $1.57 \pm 0.45 ; \operatorname{Exp}, 1.63 \pm 0.14 ; n=16 ; p=0.96)$ and in media with histamine (Ctrl, $1.75 \pm 0.15 ; \operatorname{Exp}, 2.47 \pm 0.24 ; n=14 ; p<$ 0.005); neurons coexpressing GluR1-GFP and PTEN(dn)-RFP from KO mice cultured in normal media (Ctrl, $1.76 \pm 0.15$; Exp, $1.93 \pm 0.12 ; n=14 ; p=0.30$ ), in media with histamine ( $(t r l, 1.74 \pm 0.17 ; \operatorname{Exp}, 2.93 \pm 0.30 ; n=12 ; p<0.01$ ), and in media with histamine and $10 \mu \mathrm{MLY} 294002$ (Ctrl, 1.68 $\pm 0.08 ;$ Exp, 1.74 $\pm 0.09 ; n=18 ; p=0.65$ ); GluR1-GFP-expressing CA1 neurons from awake KO (Ctrl, $1.56 \pm 0.10 ; \operatorname{Exp}, 1.64 \pm 0.11 ; n=16 ; p=0.76)$ and WT (Ctrl, 1.63 $\pm 0.10 ; \operatorname{Exp}, 2.31 \pm 0.17 ; n=16 ; p<$ 0.005) mice; and GluR1-GFP-IRES-Ras(wt)-RFP-expressing (Ctrl, 1.33 \pm 0.18 ; Exp, 1.81 $\pm 0.23 ; n=12 ; p<0.005$ ) CA1 neurons from awake K0 mice. AMPA-R-mediated current amplitudes and SEs were normalized to average values in control cells. ${ }^{*} p \leq 0.05$ (Wilcoxon test). apses in FMR1 knock-out mice (Li et al., 2002; Zhao et al., 2005; Meredith et al., 2007).

The behavior of FMR1 knock-out mice has been extensively examined, but whether learning is impaired in these mice remains unclear (The Dutch-Belgian Fragile X Consortium, 1994; D'Hooge et al., 1997; Paradee et al., 1999; Dobkin et al., 2000; Van Dam et al., 2000; Frankland et al., 2004; Zhao et al., 2005). A closer scrutiny of the literature reveals that FMR1 knock-out mice have only mild or no defect in the hippocampus-dependent spatial learning assessed using the classic Morris water maze test 
A Ctrl

$$
\begin{aligned}
& \text { GluR1-GFP-IRES GluR1-GFP } \\
& \text {-Ras(wt)-RFP }
\end{aligned}
$$
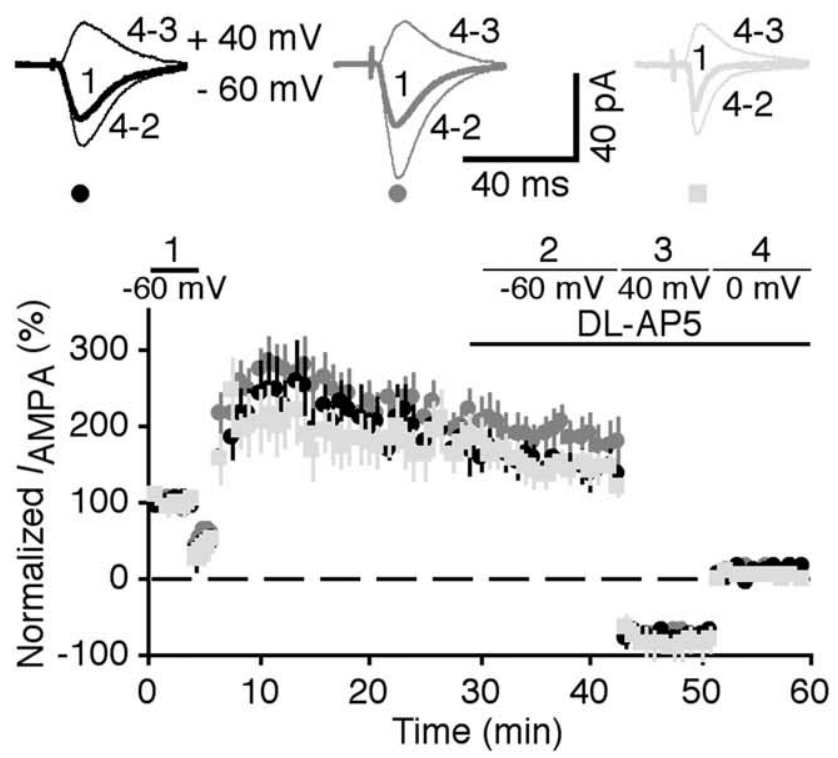

B

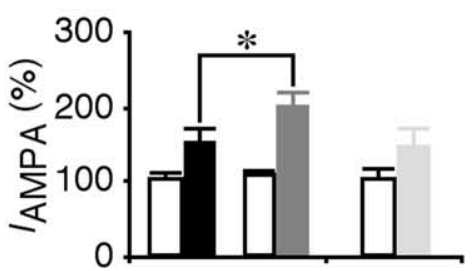

\section{After pairing}

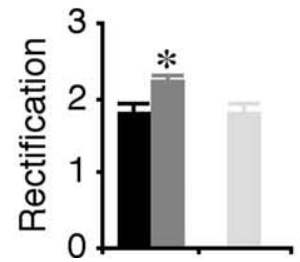

C Control Ctrl Ras(wt)-GFP
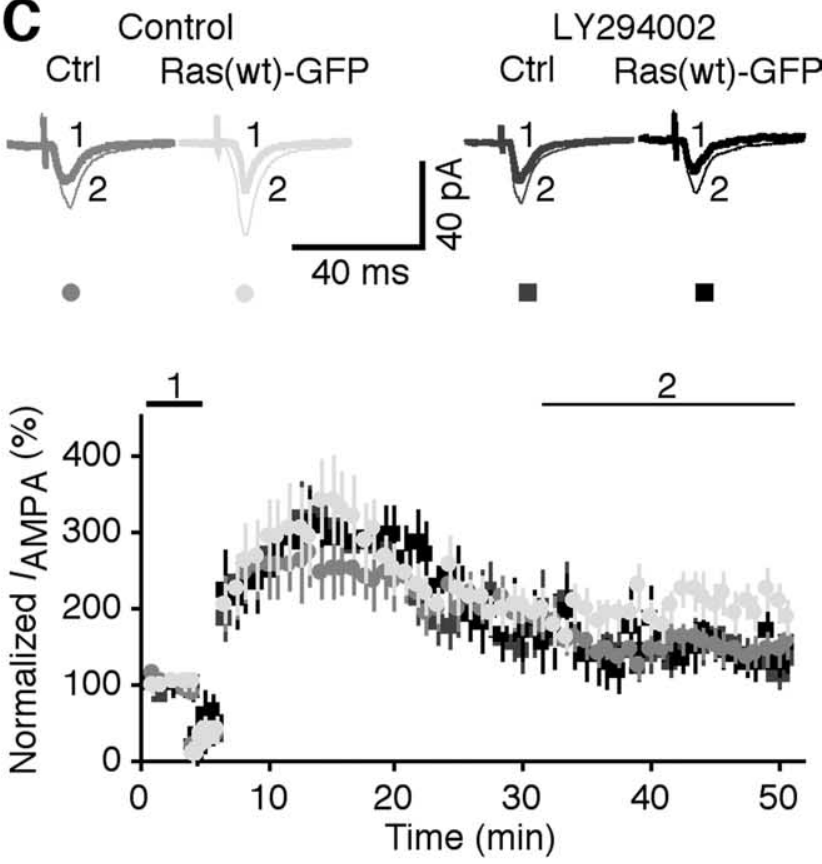

D

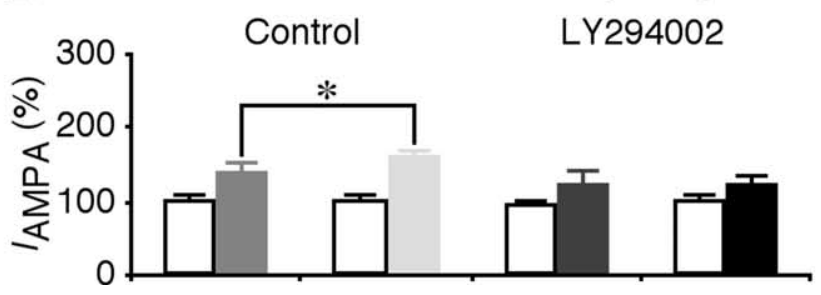

Figure 10. Enhancing Ras-PI3K-PKB signaling restores normal LTP in FMR1 K0 mice. A, Average AMPA-R-mediated synaptic responses obtained before (- $60 \mathrm{mV}$, thick trace) and after ( -60 and $+40 \mathrm{mV}$, thin traces) LTP-inducing pairing in nonexpressing (Ctrl) and GluR1-GFP-IRES-Ras(wt)-RFP- (recorded simultaneously) and GluR1-GFP- CA1 neurons from FMR1 knock-0ut mice. Bottom, Normalized simultaneously evoked responses recorded from all CA1 neurons against time. $B$, Steady-state AMPA response amplitudes (Ctrl, $18.0 \pm 12.9 \%$, from initial $-32.6 \pm 3.6 \mathrm{pA}$; Exp, $184.4 \pm 21.3 \%$, from initial $-34.2 \pm 2.8$ pA, $n=14 ; p<0.05$ ) and rectification (Ctrl, $1.78 \pm 0.10 ;$ Exp, $2.18 \pm 0.13 ; n=14 ; p<0.01$ ) in GluR1-GFP-IRES-Ras(wt)-RFP-expressing (Exp) neurons from FMR1 knock-out mice after pairing, and steady-state AMPA response amplitudes (144.9 $\pm 10.6 \% ; n=12 ;$ from initial $-26.1 \pm 5.0 \mathrm{pA})$ and rectification (Ctrl, $1.77 \pm 0.14 ; n=12$; $p<0.01$ ) in GluR1-GFP-expressing neurons from FMR1 knock-out mice after pairing. Note enhanced rectification in GluR1-GFP-IRES-Ras(wt)-RFP-expressing, but not in control nonexpressing, neurons compared with GluR1-GFP-expressing neurons (Ctrl, $n=14$; GluR1-GFP, $n=12 ; p=0.90$; Mann-Whitney rank-sum nonparametric tests). C, Average AMPA-R-mediated synaptic responses obtained before ( $-60 \mathrm{mV}$, thick trace) and after ( $-60 \mathrm{mV}$, thin trace) LTP-inducing pairing in nonexpressing (Ctrl) and Ras(wt)-GFP-expressing (recorded simultaneously) CA1 neurons from FMR1 knock-out mice bathed in normal solution (top left) or solution containing $10 \mu \mathrm{m}$ LY294002 (top right). Bottom, Normalized simultaneously evoked responses recorded from all CA1 neurons against time. $D$, Steady-state AMPA response amplitudes in CA1 neurons from knock-out mice bathed in normal solution (Ctrl, $137.5 \pm 8.4 \%$, from initial $-29.4 \pm 3.1 \mathrm{pA}$; Exp, $174.0 \pm$ $12.8 \%$, from initial $-28.4 \pm 3.1 \mathrm{pA} ; n=18 ; p<0.01$ ) or solution containing $10 \mu \mathrm{m} \mathrm{LY} 294002$ (Ctrl, $137.2 \pm 15.8 \%$, from initial $-26.9 \pm 2.0 \mathrm{pA} ;$ Exp, $139.1 \pm 18.9 \%$, from initial $-28.3 \pm$ $4.3 \mathrm{pA} ; n=18 ; p=0.91$ ) before and after pairing. AMPA-R-mediated current amplitudes and SEs were normalized to average initial values in control cells or GluR1-GFP-expressing neurons. * $p \leq$ 0.05 (Wilcoxon test).

(D’Hooge et al., 1997; Paradee et al., 1999; Dobkin et al., 2000; Van Dam et al., 2000), but do exhibit learning impairment in a modified task, the ensuing reversal trials of the Morris water maze test (The Dutch-Belgian Fragile X Consortium, 1994; D'Hooge et al., 1997). Given that spatial learning is preserved in GluR1 knock-out mice, or is independent of GluR1, whereas the modified Morris task seems to require trial specific memory (or association of the trial-related information), which is dependent on GluR1 (Zamanillo et al., 1999; Schmitt et al., 2005), these behavioral data are consistent with our finding that GluR1-dependent, but not GluR2L-dependent, synaptic potentiation is impaired in FMR1 knock-out mice. Moreover, GluR1 is required for other versions of associative learning (Schmitt et al., 2004; Rumpel et al., 2005; Hu et al., 2007; Matsuo et al., 2008). Consistent with our finding of impaired GluR1-dependent plasticity, FMR1 knockout mice performed poorly in fear conditioning, a classic form of associative learning (Paradee et al., 1999; Van Dam et al., 2000; Zhao et al., 2005) (but see Dobkin et al., 2000). Finally, human patients with fragile X syndrome exhibit impairments in obtaining associative experience-required academic skills, but not in learning isolated, direct experience-dependent tasks (Loesch et al., 2004; Roberts et al., 2005). Thus, the correspondence between our results and previous behavioral observations suggests a specific link between Ras-PI3K-PKB signaling, synaptic GluR1 trafficking, and associative learning.

In addition to the impairment of GluR1-dependent, but not GluR2L-dependent LTP reported in this study, mGluRdependent, but not NMDA-R-dependent, LTD is modestly enhanced in CA1 neurons of FMR1 knock-out mice (Huber et al., 2002; Hou et al., 2006). Because the reduced LTP decreases synaptic delivery of AMPA-Rs and enhanced mGluR-dependent LTD increases synaptic removal of AMPA-Rs (Malinow and 
Malenka, 2002), whereas basal transmission (AMPA-R- and NMDA-R-mediated) is unchanged in FMR1 knock-out mice (Fig. 2) (Godfraind et al., 1996; Huber et al., 2002; Zhao et al., 2005), depotentiation, the other major form of synaptic plasticity, is likely to be reduced in FMR1 knock-out mice. Indeed, the translational regulation of mRNA (Brown et al., 2001), protein expression, and activity of small GTPase Rap2 (our unpublished observations), which controls depotentiation (Zhu et al., 2005), are all altered in FMR1 knock-out mice. Interestingly, upregulated mGluR-dependent LTD, which removes synaptic GluR2/3 AMPA-Rs (Hsieh et al., 2006), seems responsible for the impaired inhibitory avoidance extinction in FMR1 knock-out mice (Dölen et al., 2007). These results highlight the importance of linking forms of altered synaptic plasticity, types of impaired AMPA-R trafficking and distorted cognitive behaviors in future fragile $\mathrm{X}$ research.

\section{Ras signaling and fragile $\mathrm{X}$ syndrome}

Dependent on the cell type, small GTPase Ras regulates cellular processes via multiple downstream pathways, including MEKERK and PI3K-PKB (Bos, 1995; White et al., 1995; RodriguezViciana et al., 1997; Tian et al., 2004). In neuronal cells, the RasMEK-ERK and Ras-PI3K-PKB pathways differentially control GluR2L- and GluR1-dependent synaptic potentiation (Zhu et al., 2002; Qin et al., 2005). Here, we report a prominent defect in signal coupling between Ras and PI3K-PKB, explaining the profound impairment in GluR1-dependent LTP in FMR1 knock-out mice. Moreover, enhancing Ras-PI3K signaling restores normal synaptic delivery of GluR1 and LTP. Interestingly, two recent studies have demonstrated that BDNF (Lauterborn et al., 2007), and enriched environments (Meredith et al., 2007), which stimulate neurotrophic factor release (Young et al., 1999; Ickes et al., 2000; Gobbo and O'Mara, 2004), rescue the impaired LTP in FMR1 knock-out mice. Because neurotrophic factors stimulate PI3K signaling (Patapoutian and Reichardt, 2001), these findings support the notion that enhancing PI3K signaling may be an effective way to restore normal synaptic plasticity in knock-out mice.

In the present study, we have observed several unexpected Ras activities in FMR1 knock-out mice. For example, a higher threshold for PI3K-PKB signaling than MEK-ERK signaling in knockout mice was not predicted by our previous report, which shows that neuromodulators and increased vigilance simultaneously stimulate PI3K-PKB and MEK-ERK signaling (Qin et al., 2005). This finding may be explained if Ras signals Ras-PI3K and MEKERK in different subcellular compartments at synapses. Moreover, the upregulated Ras activity but reduced downstream signaling in knock-out mice is surprising. This result may imply that subcellular trafficking of Ras to proper domains, particularly to domains for PI3K signaling, is tightly regulated but impaired in knock-out mice given that proper locations or interactions of signaling components are crucial for Ras signaling (Jura et al., 2006; Gupta et al., 2007). Finally, it was not anticipated that Ras(wt) and PTEN(dn) expressions rescue GluR1 delivery and GluR1-dependent LTP, but have little effect on basal transmission (cf. Zhu et al., 2002). These results implicate steep thresholds for activating the downstream Ras signaling pathways, which are possible if only a small number of active Ras molecules at synapses (presumably those located in nanoclusters) are involved in functional signaling, and they operate as nanoswitches (all-ornone-like) (cf. Murakoshi et al., 2004; Sharma et al., 2004). Because loss of FMRP may affect mRNA translation and protein expression of Ras regulators (Zhong et al., 1999; Brown et al.,
2001; Zalfa et al., 2003), it is likely that proper trafficking and/or function of Ras is impaired at subsynaptic compartments in FMR1 knock-out mice. Our results do not completely rule out the possibility that loss of FMRP may impair the signal transduction downstream of Ras by altering the function of regulators of PI3K-PKB and MEK-ERK (Brown et al., 2001; Kim et al., 2008). However, at intact synapses, this downstream impairment is limited, if it exists at all, because these signaling pathways are mostly functional when stimulated (Fig. 8).

The notion of reduced Ras-PI3K-PKB signaling immediately provides a mechanism for other prominent features associated with fragile $\mathrm{X}$ syndrome, including dendritic spine dysmorphogenesis (Comery et al., 1997; Irwin et al., 2001; Nimchinsky et al., 2001; Govek et al., 2005; Grossman et al., 2006), facial dysmorphism (O'Donnell and Warren, 2002; Schubbert et al., 2007), and reduced risk of cancer (Hanahan and Weinberg, 2000; SchultzPedersen et al., 2001). Inhibiting the Ras-PI3K-PKB signaling pathway is considered as a useful therapeutic approach for treating cancer; a number of compounds that inhibit PI3K-PKB signaling are currently in the late preclinical development or early phases of clinical trials (Downward, 2006). However, our findings raise some concern of unwanted side effects of these PI3K$\mathrm{PKB}$ signaling inhibitors, and underscore the importance of developing tissue- or cell-specific therapeutic approaches in the future to treat cancer and fragile $\mathrm{X}$ patients.

\section{References}

Bagni C, Greenough WT (2005) From mRNP trafficking to spine dysmorphogenesis: the roots of fragile X syndrome. Nat Rev Neurosci 6:376-387.

Bekkers JM (1993) Enhancement by histamine of NMDA-mediated synaptic transmission in the hippocampus. Science 261:104-106.

Bos JL (1995) A target for phosphoinositide 3-kinase: Akt/PKB. Trends Biochem Sci 20:441-442.

Brown V, Jin P, Ceman S, Darnell JC, O’Donnell WT, Tenenbaum SA, Jin X, Feng Y, Wilkinson KD, Keene JD, Darnell RB, Warren ST (2001) Microarray identification of FMRP-associated brain mRNAs and altered mRNA translational profiles in fragile X syndrome. Cell 107:477-487.

Comery TA, Harris JB, Willems PJ, Oostra BA, Irwin SA, Weiler IJ, Greenough WT (1997) Abnormal dendritic spines in fragile X knockout mice: maturation and pruning deficits. Proc Natl Acad Sci US A 94:5401-5404.

Costa RM, Silva AJ (2003) Mouse models of neurofibromatosis type I: bridging the GAP. Trends Mol Med 9:19-23.

de Rooij J, Bos JL (1997) Minimal Ras-binding domain of Rafl can be used as an activation-specific probe for Ras. Oncogene 14:623-625.

De Simoni A, Griesinger CB, Edwards FA (2003) Development of rat CA1 neurones in acute versus organotypic slices: role of experience in synaptic morphology and activity. J Physiol 550:135-147.

D’Hooge R, Nagels G, Franck F, Bakker CE, Reyniers E, Storm K, Kooy RF, Oostra BA, Willems PJ, De Deyn PP (1997) Mildly impaired water maze performance in male Fmr1 knockout mice. Neuroscience 76:367-376.

Dobkin C, Rabe A, Dumas R, El Idrissi A, Haubenstock H, Brown WT (2000) Fmrl knockout mouse has a distinctive strain-specific learning impairment. Neuroscience 100:423-429.

Dölen G, Osterweil E, Rao BS, Smith GB, Auerbach BD, Chattarji S, Bear MF (2007) Correction of Fragile X Syndrome in Mice. Neuron 56:955-962.

Downward J (2006) Signal transduction. Prelude to an anniversary for the RAS oncogene. Science 314:433-434.

Frankland PW, Wang Y, Rosner B, Shimizu T, Balleine BW, Dykens EM, Ornitz EM, Silva AJ (2004) Sensorimotor gating abnormalities in young males with fragile X syndrome and Fmr1-knockout mice. Mol Psychiatry 9:417-425.

Giuffrida R, Musumeci S, D’Antoni S, Bonaccorso CM, Giuffrida-Stella AM, Oostra BA, Catania MV (2005) A reduced number of metabotropic glutamate subtype 5 receptors are associated with constitutive homer proteins in a mouse model of fragile X syndrome. J Neurosci 25:8908-8916.

Gobbo OL, O'Mara SM (2004) Impact of enriched-environment housing on brain-derived neurotrophic factor and on cognitive performance after a transient global ischemia. Behav Brain Res 152:231-241. 
Godfraind JM, Reyniers E, De Boulle K, D’Hooge R, De Deyn PP, Bakker CE, Oostra BA, Kooy RF, Willems PJ (1996) Long-term potentiation in the hippocampus of fragile X knockout mice. Am J Med Genet 64:246-251.

Govek EE, Newey SE, Van Aelst L (2005) The role of the Rho GTPases in neuronal development. Genes Dev 19:1-49.

Grossman AW, Elisseou NM, McKinney BC, Greenough WT (2006) Hippocampal pyramidal cells in adult Fmrl knockout mice exhibit an immature-appearing profile of dendritic spines. Brain Res 1084:158-164.

Gu Y, Stornetta RL (2007) Synaptic plasticity, AMPA-R trafficking, and Ras-MAPK signaling. Acta Pharmacologica Sinica 28:928-936.

Gupta S, Ramjaun AR, Haiko P, Wang Y, Warne PH, Nicke B, Nye E, Stamp G, Alitalo K, Downward J (2007) Binding of ras to phosphoinositide 3 -kinase p110alpha is required for ras-driven tumorigenesis in mice. Cell 129:957-968.

Hanahan D, Weinberg RA (2000) The hallmarks of cancer. Cell 100:57-70.

Hayashi Y, Shi SH, Esteban JA, Piccini A, Poncer JC, Malinow R (2000) Driving AMPA receptors into synapses by LTP and CaMKII: requirement for GluR1 and PDZ domain interaction. Science 287:2262-2267.

Hou L, Antion MD, Hu D, Spencer CM, Paylor R, Klann E (2006) Dynamic translational and proteasomal regulation of fragile $\mathrm{X}$ mental retardation protein controls mGluR-dependent long-term depression. Neuron 51:441-454.

Hsieh H, Boehm J, Sato C, Iwatsubo T, Tomita T, Sisodia S, Malinow R (2006) AMPAR removal underlies Abeta-induced synaptic depression and dendritic spine loss. Neuron 52:831-843.

Hu H, Real E, Takamiya K, Kang MG, Ledoux J, Huganir RL, Malinow R (2007) Emotion enhances learning via norepinephrine regulation of AMPA-receptor trafficking. Cell 131:160-173.

Huber KM, Gallagher SM, Warren ST, Bear MF (2002) Altered synaptic plasticity in a mouse model of fragile $\mathrm{X}$ mental retardation. Proc Natl Acad Sci U S A 99:7746-7750.

Ickes BR, Pham TM, Sanders LA, Albeck DS, Mohammed AH, Granholm AC (2000) Long-term environmental enrichment leads to regional increases in neurotrophin levels in rat brain. Exp Neurol 164:45-52.

Irwin SA, Patel B, Idupulapati M, Harris JB, Crisostomo RA, Larsen BP, Kooy F, Willems PJ, Cras P, Kozlowski PB, Swain RA, Weiler IJ, Greenough WT (2001) Abnormal dendritic spine characteristics in the temporal and visual cortices of patients with fragile-X syndrome: a quantitative examination. Am J Med Genet 98:161-167.

Isaac JT, Ashby M, McBain CJ (2007) The role of the GluR2 subunit in AMPA receptor function and synaptic plasticity. Neuron 54:859-871.

Jaworski J, Spangler S, Seeburg DP, Hoogenraad CC, Sheng M (2005) Control of dendritic arborization by the phosphoinositide-3'-kinase-Aktmammalian target of rapamycin pathway. J Neurosci 25:11300-11312.

Jura N, Scotto-Lavino E, Sobczyk A, Bar-Sagi D (2006) Differential modification of Ras proteins by ubiquitination. Mol Cell 21:679-687.

Kim SH, Markham JA, Weiler IJ, Greenough WT (2008) Aberrant earlyphase ERK inactivation impedes neuronal function in fragile X syndrome. Proc Natl Acad Sci U S A 105:4429-4434.

Kolleker A, Zhu JJ, Schupp BJ, Qin Y, Mack V, Borchardt T, Köhr G, Malinow R, Seeburg PH, Osten P (2003) Glutamatergic plasticity by synaptic delivery of GluR-B(long)-containing AMPA receptors. Neuron 40:1199-1212.

Kumar V, Zhang MX, Swank MW, Kunz J, Wu GY (2005) Regulation of dendritic morphogenesis by Ras-PI3K-Akt-mTOR and Ras-MAPK signaling pathways. J Neurosci 25:11288-11299.

Larkum ME, Zhu JJ (2002) Signaling of layer 1 and whisker-evoked $\mathrm{Ca}^{2+}$ and $\mathrm{Na}+$ action potentials in distal and terminal dendrites of rat neocortical pyramidal neurons in vitro and in vivo. J Neurosci 22:6991-7005.

Larson J, Jessen RE, Kim D, Fine AK, du Hoffmann J (2005) Age-dependent and selective impairment of long-term potentiation in the anterior piriform cortex of mice lacking the fragile X mental retardation protein. J Neurosci 25:9460-9469.

Lauterborn JC, Rex CS, Kramár E, Chen LY, Pandyarajan V, Lynch G, Gall CM (2007) Brain-derived neurotrophic factor rescues synaptic plasticity in a mouse model of fragile X syndrome. J Neurosci 27:10685-10694.

Lei S, McBain CJ (2004) Two Loci of expression for long-term depression at hippocampal mossy fiber-interneuron synapses. J Neurosci 24:2112-2121.

Li J, Pelletier MR, Perez Velazquez JL, Carlen PL (2002) Reduced cortical synaptic plasticity and GluR1 expression associated with fragile X mental retardation protein deficiency. Mol Cell Neurosci 19:138-151.
Loesch DZ, Huggins RM, Hagerman RJ (2004) Phenotypic variation and FMRP levels in fragile X. Ment Retard Dev Disabil Res Rev 10:31-41.

Loesch DZ, Bui QM, Dissanayake C, Clifford S, Gould E, Bulhak-Paterson D, Tassone F, Taylor AK, Hessl D, Hagerman R, Huggins RM (2007) Molecular and cognitive predictors of the continuum of autistic behaviours in fragile X. Neurosci Biobehav Rev 31:315-326.

Maehama T, Dixon JE (1998) The tumor suppressor, PTEN/MMAC1, dephosphorylates the lipid second messenger, phosphatidylinositol 3,4,5trisphosphate. J Biol Chem 273:13375-13378.

Malinow R, Malenka RC (2002) AMPA receptor trafficking and synaptic plasticity. Annu Rev Neurosci 25:103-126.

Man HY, Wang Q, Lu WY, Ju W, Ahmadian G, Liu L, D’Souza S, Wong TP, Taghibiglou C, Lu J, Becker LE, Pei L, Liu F, Wymann MP, MacDonald JF, Wang YT (2003) Activation of PI3-Kinase Is Required for AMPA Receptor Insertion during LTP of mEPSCs in Cultured Hippocampal Neurons. Neuron 38:611-624.

Manning BD, Cantley LC (2007) AKT/PKB Signaling: navigating Downstream. Cell 129:1261-1274.

Matsuo N, Reijmers L, Mayford M (2008) Spine-type-specific recruitment of newly synthesized AMPA receptors with learning. Science 319:1104-1107.

Mattingly RR, Macara IG (1996) Phosphorylation-dependent activation of the Ras-GRF/CDC25Mm exchange factor by muscarinic receptors and G-protein beta gamma subunits. Nature 382:268-272.

McCormack SG, Stornetta RL, Zhu JJ (2006) Synaptic AMPA receptor exchange maintains bidirectional plasticity. Neuron 50:75-88.

Meredith RM, Holmgren CD, Weidum M, Burnashev N, Mansvelder HD (2007) Increased threshold for spike-timing-dependent plasticity is caused by unreliable calcium signaling in mice lacking fragile $\mathrm{X}$ gene FMR1. Neuron 54:627-638.

Micheletti R, Schiavone A (1990) Functional determination of McN-A-343 affinity for M1 muscarinic receptors. J Pharmacol Exp Ther 253:310-314.

Murakoshi H, Iino R, Kobayashi T, Fujiwara T, Ohshima C, Yoshimura A, Kusumi A (2004) Single-molecule imaging analysis of Ras activation in living cells. Proc Natl Acad Sci U S A 101:7317-7322.

Murga C, Laguinge L, Wetzker R, Cuadrado A, Gutkind JS (1998) Activation of Akt/protein kinase B by $\mathrm{G}$ protein-coupled receptors. A role for alpha and beta gamma subunits of heterotrimeric $G$ proteins acting through phosphatidylinositol-3-OH kinasegamma. J Biol Chem 273:19080-19085.

Nakamoto M, Nalavadi V, Epstein MP, Narayanan U, Bassell GJ, Warren ST (2007) Fragile X mental retardation protein deficiency leads to excessive mGluR5-dependent internalization of AMPA receptors. Proc Natl Acad Sci U S A 104:15537-15542.

Nimchinsky EA, Oberlander AM, Svoboda K (2001) Abnormal development of dendritic spines in FMR1 knock-out mice. J Neurosci 21:5139-5146.

Nosyreva ED, Huber KM (2006) Metabotropic receptor-dependent longterm depression persists in the absence of protein synthesis in the mouse model of fragile X syndrome. J Neurophysiol 95:3291-3295.

O’Donnell WT, Warren ST (2002) A decade of molecular studies of fragile X syndrome. Annu Rev Neurosci 25:315-338.

Paradee W, Melikian HE, Rasmussen DL, Kenneson A, Conn PJ, Warren ST (1999) Fragile X mouse: strain effects of knockout phenotype and evidence suggesting deficient amygdala function. Neuroscience 94:185-192.

Passafaro M, Piëch V, Sheng M (2001) Subunit-specific temporal and spatial patterns of AMPA receptor exocytosis in hippocampal neurons. Nat Neurosci 4:917-926.

Patapoutian A, Reichardt LF (2001) Trk receptors: mediators of neurotrophin action. Curr Opin Neurobiol 11:272-280.

Qin Y, Zhu Y, Baumgart JP, Stornetta RL, Seidenman K, Mack V, van Aelst L, Zhu JJ (2005) State-dependent Ras signaling and AMPA receptor trafficking. Genes Dev 19:2000-2015.

Riojas RA, Kikani CK, Wang C, Mao X, Zhou L, Langlais PR, Hu D, Roberts JL, Dong LQ, Liu F (2006) Fine tuning PDK1 activity by phosphorylation at Ser163. J Biol Chem 281:21588-21593.

Roberts JE, Schaaf JM, Skinner M, Wheeler A, Hooper S, Hatton DD, Bailey DB, Jr (2005) Academic skills of boys with fragile X syndrome: profiles and predictors. Am J Ment Retard 110:107-120.

Rodriguez-Viciana P, Warne PH, Khwaja A, Marte BM, Pappin D, Das P, Waterfield MD, Ridley A, Downward J (1997) Role of phosphoinositide 
3-OH kinase in cell transformation and control of the actin cytoskeleton by Ras. Cell 89:457-467.

Rumpel S, LeDoux J, Zador A, Malinow R (2005) Postsynaptic receptor trafficking underlying a form of associative learning. Science 308:83-88.

Schmitt WB, Arianpour R, Deacon RM, Seeburg PH, Sprengel R, Rawlins JN, Bannerman DM (2004) The role of hippocampal glutamate receptor-Adependent synaptic plasticity in conditional learning: the importance of spatiotemporal discontiguity. J Neurosci 24:7277-7282.

Schmitt WB, Sprengel R, Mack V, Draft RW, Seeburg PH, Deacon RM, Rawlins JN, Bannerman DM (2005) Restoration of spatial working memory by genetic rescue of GluR-A-deficient mice. Nat Neurosci 8:270-272.

Schubbert S, Bollag G, Shannon K (2007) Deregulated Ras signaling in developmental disorders: new tricks for an old dog. Curr Opin Genet Dev 17:15-22.

Schultz-Pedersen S, Hasle H, Olsen JH, Friedrich U (2001) Evidence of decreased risk of cancer in individuals with fragile X. Am J Med Genet 103:226-230

Sharma P, Varma R, Sarasij RC, Ira, Gousset K, Krishnamoorthy G, Rao M, Mayor S (2004) Nanoscale organization of multiple GPI-anchored proteins in living cell membranes. Cell 116:577-589.

Skinner M, Hooper S, Hatton DD, Roberts J, Mirrett P, Schaaf J, Sullivan K, Wheeler A, Bailey DB Jr (2005) Mapping nonverbal IQ in young boys with fragile X syndrome. Am J Med Genet A 132:25-32.

Steriade M, McCarley RW (1990) Brainstem control of wakefulness and sleep. New York: Plenum.

Sun H, Lesche R, Li DM, Liliental J, Zhang H, Gao J, Gavrilova N, Mueller B, Liu X, Wu H (1999) PTEN modulates cell cycle progression and cell survival by regulating phosphatidylinositol 3,4,5,-trisphosphate and Akt/ protein kinase B signaling pathway. Proc Natl Acad Sci USA 96:6199-6204.

Tada T, Sheng M (2006) Molecular mechanisms of dendritic spine morphogenesis. Curr Opin Neurobiol 16:95-101.

The Dutch-Belgian Fragile X Consortium (1994) Fmrl knockout mice: a model to study fragile X mental retardation. Cell 78:23-33.

Thomas GM, Huganir RL (2004) MAPK cascade signalling and synaptic plasticity. Nat Rev Neurosci 5:173-183.

Tian X, Gotoh T, Tsuji K, Lo EH, Huang S, Feig LA (2004) Developmentally regulated role for Ras-GRFs in coupling NMDA glutamate receptors to Ras, Erk and CREB. EMBO J 23:1567-1575.

Van Dam D, D'Hooge R, Hauben E, Reyniers E, Gantois I, Bakker CE, Oostra BA, Kooy RF, De Deyn PP (2000) Spatial learning, contextual fear con- ditioning and conditioned emotional response in Fmr1 knockout mice. Behav Brain Res 117:127-136.

White MA, Nicolette C, Minden A, Polverino A, Van Aelst L, Karin M, Wigler MH (1995) Multiple Ras functions can contribute to mammalian cell transformation. Cell 80:533-541.

Young D, Lawlor PA, Leone P, Dragunow M, During MJ (1999) Environmental enrichment inhibits spontaneous apoptosis, prevents seizures and is neuroprotective. Nat Med 5:448-453.

Zalfa F, Giorgi M, Primerano B, Moro A, Di Penta A, Reis S, Oostra B, Bagni C (2003) The fragile X syndrome protein FMRP associates with BC1 RNA and regulates the translation of specific mRNAs at synapses. Cell 112:317-327.

Zamanillo D, Sprengel R, Hvalby O, Jensen V, Burnashev N, Rozov A, Kaiser KM, Koster HJ, Borchardt T, Worley P, Lübke J, Frotscher M, Kelly PH, Sommer B, Andersen P, Seeburg PH, Sakmann B (1999) Importance of AMPA receptors for hippocampal synaptic plasticity but not for spatial learning. Science 284:1805-1811.

Zhang W, Linden DJ (2003) The other side of the engram: experiencedriven changes in neuronal intrinsic excitability. Nat Rev Neurosci 4:885-900.

Zhao MG, Toyoda H, Ko SW, Ding HK, Wu LJ, Zhuo M (2005) Deficits in trace fear memory and long-term potentiation in a mouse model for fragile X syndrome. J Neurosci 25:7385-7392.

Zhong N, Ju W, Nelson D, Dobkin C, Brown WT (1999) Reduced mRNA for G3BP in fragile X cells: evidence of FMR1 gene regulation. Am J Med Genet 84:268-271.

Zhu JJ (2000) Maturation of layer 5 neocortical pyramidal neurons: amplifying salient layer 1 and layer 4 inputs by $\mathrm{Ca}^{2+}$ action potentials in adult rat tuft dendrites. J Physiol 526:571-587.

Zhu JJ, Connors BW (1999) Intrinsic firing patterns and whisker-evoked synaptic responses of neurons in the rat barrel cortex. J Neurophysiol 81:1171-1183.

Zhu JJ, Esteban JA, Hayashi Y, Malinow R (2000) Postnatal synaptic potentiation: delivery of GluR4-containing AMPA receptors by spontaneous activity. Nat Neurosci 3:1098-1106.

Zhu JJ, Qin Y, Zhao M, Van Aelst L, Malinow R (2002) Ras and Rap control AMPA receptor trafficking during synaptic plasticity. Cell 110:443-455.

Zhu Y, Pak D, Qin Y, McCormack SG, Kim MJ, Baumgart JP, Velamoor V, Auberson YP, Osten P, van Aelst L, Sheng M, Zhu JJ (2005) Rap2-JNK removes synaptic AMPA receptors during depotentiation. Neuron 46: 905-916. 